\title{
Methodology of Thermal Research in Materials Engineering
}

\author{
Anna Biedunkiewicz
}

Additional information is available at the end of the chapter

http://dx.doi.org/10.5772/51415

\section{Introduction}

The mechanism of nanostructural carbides synthesis, and chemical activity of nanoparticles in oxidizing environments, even occurring in trace amounts in high-purity gases, require application of precise methods and performing investigations for a wide range of parameters. The methodology of investigation and the way of determination of selected synthesis conditions have been described in this work. Appropriate selection of investigation methodology enables understanding of process mechanisms, performing quantitative analysis and then correct determination of their conditions.

Good basis for analysis of the processes proceeding with participation of solids are kinetic studies. Kinetic studies can be carried out under isothermal or non-isothermal conditions. The transitions with participation of solid reagents usually proceed in many stages. Each step should be treated as an independent process. The measurements indispensable for identification of process stages and reagents are usually carried out by methods of thermal analysis. There are elaborated different methods of kinetic studies. They are the subject of ongoing discussion [1].

Methods of process kinetics are of great significance for materials engineering. In work [2], for example, kinetics of carbothermal synthesis of $\beta$-SiC was investigated; in work $[3,4]$ kinetics and mechanism of carbothermal reduction of $\mathrm{MoO}_{3}$ to $\mathrm{Mo}_{2} \mathrm{C}$; in work [5] kinetics of thermal decomposition of $\mathrm{NH}_{4} \mathrm{VO}_{3}$; in work [6] kinetics of nanometric ceramic materials synthesis in argon and their oxidation in dry air were investigated.

Kinetic studies of manufacturing process of carbides of the metals, e.g. titanium, vanadium, niobium, tantalum or silicon, are of particular significance. These metal carbides belong to the group of ceramic materials known as conventionally hard materials, high wear and oxidation resistance. This results from the character of chemical bound and crystallographic structure. The fabrication of ultrafine-grain ceramics by powder- metallurgical processes 
involves a number of serious difficulties. In particular, it is necessary to use ultrafine powders and to optimize sintering conditions so as to prevent grain growth. Due to their high reactivity of such powders, the process must be run in an inert atmosphere. The composites containing nanostructural carbides show higher strengthening in comparison to their microstructural equivalents [7].

Synthesis of these materials is most often carried out by carbothermal reduction of oxides or precursors containing metal-oxygen-carbon conjugation [1,2,8,9,10]. Other attractive synthesis routes are processes of decomposition of organometallic precursors or synthesis carried out with participation of hydrocarbons, eg. $\mathrm{CH}_{4}$ or $\mathrm{C}_{6} \mathrm{H}_{6}$, and salts of transition metals [11,12]. Carbothermal synthesis of the carbides proceeds through stages of oxides formation and than oxycarbides formation being the intermediate products of the syntheses. In the latter case the intermediate products are low-stoichiometry carbides of high vacancies concentration resulting from stability range of these phases in equilibrium metal-carbide system.

Presence of oxygen atoms in $\mathrm{MC}_{x} \mathrm{O}_{1-x}$ lattice or high concentration of carbon vacancies in $\mathrm{MC}_{1-\mathrm{x}}$ lattice cause reduction in hardness and wear and oxidation resistance $[12,13]$.

The synthesis stages leading to elimination of above mentioned lattice defects and obtainment of high-stoichiometry, oxygen stripped carbides, characterized by best properties, proceeds in temperature range above $1000^{\circ} \mathrm{C}$.

At the example of decomposition processes investigations process kinetics of the decomposition of $\mathrm{NH}_{4} \mathrm{VO}_{3}$ has been analysed. The issues concerning kinetics of those processes have been presented at the example of thermal decomposition of $\mathrm{NH}_{4} \mathrm{VO}_{3}$ to $\mathrm{V}_{2} \mathrm{O}_{5}$ in dry air. Vanadium carbides, carbonitrides and borides are known ceramic materials [1416]. $\mathrm{NH}_{4} \mathrm{VO}_{3}$ could be used in these processes as a precursor. The results of investigations on thermal decomposition of $\mathrm{NH}_{4} \mathrm{VO}_{3}$ in dry air have been presented. The base of kinetic description of these processes were termoanalytical TG-DSC measurements. They allowed identifying of intermediate and final products, distinguishing stages of the process, determination of their temperature ranges and acquisition the quantitative description. Process kinetics of the stages were described by Kissinger's method, isoconversional method and applying Coats- Redfern equation.

Obtaining the carbides of high carbonization degree, remaining the right grains size and properties, is essential. Selection of parameters meeting these requirements is difficult. Kinetic studies have significance during investigations of conversions proceeding with use of nanomaterials [17]. In the process of TiC synthesis by sol-gel method, described in work [6], the intermediate product is low stoichiometric $\mathrm{MC}_{1-\mathrm{x}}(\mathrm{x} \leq 0.3)$. Carbides nucleate and grow in the carbon matrix. The process is carried out in argon. Describing kinetics, CoatsRedfern's equation was applied. Kinetic models of stages were identified basing on statistical evaluation and compliance to a large extent of conversion degrees of stages calculated and determined from termoanalytical measurements. While building the kinetic models of the processes, the results of measurements were treated as statistic values. A system of a complex analysis of measurements results was developed with the use of 
artificial neuron networks. Kinetics and by the same, the mechanism of the process of oxidation of nanocrystalline carbides in form of powder were tested, and they were subjected to evaluation based on the comparison of the oxidation rate values.

The possibility to remove the carbon matrix in reaction with oxygen was considered during analysis of the kinetics of the process of $\mathrm{TiC}_{\mathrm{x}} / \mathrm{C}$ nanocomposite oxidation in dry air. It was proved that it was not possible to purify the obtained nc-TiC by burning in the air the carbon matrix, contained in the system.

\section{Thermal decomposition of $\mathrm{NH}_{4} \mathrm{VO}_{3}$}

\subsection{Methods kinetic analysis}

It is assumed that the rate of non-catalytic, heterophase reactions depends on temperature, conversion degree and pressure

$$
r=\frac{d \alpha}{d t}=\phi(T, \alpha, P)
$$

After separation of variables we obtain

$$
\frac{d \alpha}{d t}=k(T) f(\alpha) h(P)
$$

Under thermogravimetric measurements conditions $h(P) \approx 1$ [18]. Then

$$
\frac{d \alpha}{d t}=k(T) f(\alpha)
$$

Separation of variables means that $\mathrm{k}(\mathrm{T})$ function should not depend on conversion degree, and function $f(\alpha)$ should not depend on temperature. Function $k(T)$ is described by Arrhenius equation

$$
k(T)=A \exp \left(-\frac{E}{R T}\right)
$$

$\mathrm{k}(\mathrm{T})$ function maintains its exponential character in relatively narrow range of temperature. Assuming $\mathrm{T}=0$ as integration limit this range is exceeded since $\mathrm{k}(\mathrm{T})$ tends asymptotically to the limit values (at $\mathrm{T} \rightarrow o$ and $\mathrm{T} \rightarrow \infty$ ).

By combining (3) and (4) we obtain

$$
\frac{d \alpha}{d t}=A \exp \left(-\frac{E}{R T}\right) f(\alpha)
$$

Thus, for isothermal conditions we have 


$$
g(\alpha)=\int_{o}^{\alpha} \frac{d \alpha}{f(\alpha)}=k(T) \mathrm{t}
$$

For non-isothermal conditions, at a linear heating rate of sample $\frac{d T}{d t}=\beta$ we obtain

$$
g(\alpha)=\frac{A}{\beta} \int_{T \alpha=0}^{T \alpha=1} \exp \left(-\frac{E}{R T}\right) d T
$$

The integral has no analytical solution. An important approximate solution is the CoatsRedfern equation [12]

$$
\ln \left[\frac{g(\alpha)}{T^{2}}\right]=F(T)=\ln \left[\frac{A R}{\beta E}\left(1-\frac{2 R T_{m}}{E}\right)\right]-\frac{E}{R T}
$$

Based on experimental data for each stage the form of the $f(\alpha)$ or $g(\alpha)$ function most consistent with the experimental data and the parameters of Arrhenius equation $\mathrm{A}$ and $\mathrm{E}$ should be determined.

During standard thermogravimetric measurements the temperature of the sample, the TG, DTG and HF functions and the mass spectra of evolved gaseous products are recorded. Solid products are identified by XRD method. On this basis the division of the process into stages is made and $\alpha(T)$ dependencies are determined for the stages. The methods of measurement results elaboration and kinetic models recommended by ICTAC Kinetics Comittee are given in work [1]. These include in particular Kissinger's method and isoconversional method.

\subsubsection{Kissinger's method}

The basis of Kissinger's method are the parameters describing the process rate $d^{2} \alpha \quad\left(\mathrm{T}_{\mathrm{m}}\right.$, $\alpha_{\mathrm{m}}$ ), determined at different heating rates of samples [14]. For maximum $\frac{d^{2} \alpha}{d t^{2}}=0$. By differentiating equation (5) we obtain

$$
\frac{d^{2} \alpha}{d t^{2}}=\left\{\frac{E \beta}{R T_{m}^{2}}+A f^{\prime}\left(\alpha_{m}\right) \exp \left[-\frac{E}{R T_{m}}\right]\right\}\left(\frac{d \alpha}{d t}\right)_{m}=0
$$

Since $\left(\frac{d \alpha}{d t}\right)_{m} \neq 0$, therefore

$$
\frac{E \beta}{R T_{m}^{2}}=-A f^{\prime}\left(\alpha_{m}\right) \exp \left[-\frac{E}{R T_{m}}\right]
$$

There should be added that the formula (10) requires that $f^{\prime}\left(\alpha_{m}\right)<0$. In this method therefore only kinetic models fulfilling this condition can be used. 
By transforming (10) and adapting the result to the measurements performed at different heating rates of samples the Kissinger equation (11) is obtained

$$
\ln \left(\frac{\beta_{i}}{T_{m, i}^{2}}\right)=\ln \left[-\frac{A R}{E} f^{\prime}\left(\alpha_{m}\right)\right]-\frac{E}{R T_{m, i}}
$$

While performing calculations, $\ln \left(\frac{\beta_{i}}{T_{m, i}^{2}}\right) \div \frac{1000}{T_{m, i}}$ charts are prepared. Then the activation energy $E$ and the value of expression $\ln \left[-\frac{A R}{E} f^{\prime}\left(\alpha_{m}\right)\right]=B$ are calculated by linear regression method.

Knowing $\mathrm{B},-A f^{\prime}\left(\alpha_{m}\right)$ is calculated from equation (12)

$$
-A f^{\prime}(\alpha)=\frac{E}{R} \exp (B)
$$

To calculate A one needs to know the kinetic model for a given stage (form of the function $f(\alpha)$ ). The kinetic model most consistent with the experimental data, of the tested models, was established by analyzing the trajectories of $\mathrm{Y}(\mathrm{T})$ function depending on $\alpha(\mathrm{T})$. The conversion degrees $\alpha(\mathrm{T})$ for the stages were estimated on the basis of experimental data, whereas the $\mathrm{Y}(\mathrm{T})$ function was calculated from the formula

$$
Y(T)=\frac{A f^{\prime}\left(\alpha_{m}\right)}{\beta_{i}} \int_{T_{\alpha=0}}^{T_{\alpha=1}} \exp \left[-\frac{E}{R T}\right] d T
$$

For the stage A $f^{\prime}\left(\alpha_{m}\right) \approx$ const. The integral was calculated numerically. There should be added that at constant activation energy, trajectories of $\frac{1}{\beta i} \int_{T \alpha=0}^{T \alpha=1} \exp \left[-\frac{E}{R T}\right] d T$ functions depending on the conversion degree, for different $\beta_{\mathrm{i}}$, should be the same. The ranges

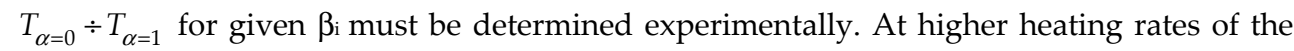
samples there should be wider temperature range $T_{\alpha=0} \div T_{\alpha=1}$. This is consistent with DTG and HF charts. After determining the form of the function $f(\alpha)$ the derivative $f^{\prime}\left(\alpha_{m}\right)$ is calculated. Knowing $A f^{\prime}\left(\alpha_{m}\right)$ and $f^{\prime}\left(\alpha_{m}\right)$ Arrhenius coefficient A is calculated.

\subsubsection{Isoconversional method}

In the the isoconversional method equation (5), obtained after separation of variables, is also used. Differentiating (5) with respect to $\partial T^{-1}$ we obtain 


$$
\left[\frac{\partial \ln \left(\frac{d \alpha}{d t}\right)}{\partial T^{-1}}\right]_{\alpha}=\left[\frac{\partial \ln k(T)}{\partial T^{-1}}\right]_{\alpha}+\left[\frac{\partial f(\alpha)}{\partial T^{-1}}\right]_{\alpha}
$$

For $\alpha=$ const we have

$$
\left[\frac{\partial \ln \left(\frac{d \alpha}{d t}\right)}{\partial T^{-1}}\right]_{\alpha}=-\frac{E_{\alpha}}{R}
$$

Integrating (15), taking into account that $\frac{d T}{d t}=\beta$, and generalizing the result for different $\beta_{\mathrm{i}}$ we obtain

$$
\ln \left[\beta_{i}\left(\frac{d \alpha}{d t}\right)_{\alpha, i}\right]=\text { const }-\frac{E_{\alpha}}{R T_{\alpha . i}}
$$

Integration constant, according to equation (5), is equal $\ln \left[f(\alpha) A_{\alpha}\right]$. Equation (16) therefore takes the form

$$
\ln \left[\beta_{i}\left(\frac{d \alpha}{d t}\right)_{\alpha, i}\right]=\ln \left[f(\alpha) A_{\alpha}\right]-\frac{E_{\alpha}}{R T_{\alpha, i}}
$$

It should be added that the introduction of the coefficients $A_{\alpha}$ and $E_{\alpha}$ depending on conversion degree does not comply with the principle of separation of variables. Equation (17) is used in the differential isoconversional method. The basis of the reaction rate calculations are reaction rates $\left(\frac{d \alpha}{d t}\right)_{\alpha, i}$ determined for selected conversion degrees and different $\beta_{i}$ and the corresponding to them temperature values $T_{\alpha}{ }_{\alpha}$.

In the case of the integral isoconversional method the basis for calculations, for isothermal conditions, is equation

$$
g(\alpha)=A \exp \left(-\frac{E}{R T}\right) t
$$

Activation energy, in this case, is calculated from the formula

$$
\ln t_{\alpha, i}=\ln \left[\frac{g(\alpha)}{A_{\alpha}}\right]+\frac{E_{\alpha}}{R T_{\alpha}}
$$


The time of obtaining the assumed conversion degree at different temperatures was designated by $t_{\alpha, i}$. The charts of $\ln t_{\alpha, i} \div \frac{1000}{T_{i}}$ are constructed. The parameters of equation (19) are calculated by linear regression method. For non-isothermal conditions there is no analytical solution. During the calculations of activation energy there are used approximate equations of general form

$$
\ln \left(\frac{\beta_{i}}{T_{\alpha, i}^{B}}\right)=\text { const }-C \frac{E_{\alpha}}{R T_{\alpha}}
$$

In this work the Kissinger's-Akoshira-Sunose equation was used

$$
\ln \left(\frac{\beta_{i}}{T_{\alpha, i}^{2}}\right)=\text { const }-\frac{E_{\alpha}}{R T_{\alpha}}
$$

In this case the charts of $\ln \left(\frac{\beta_{i}}{T_{\alpha, i}^{2}}\right) \div \frac{1000}{T \alpha}$ are constructed. The parameters of this equation are calculated by linear regression method.

\subsection{Experimental}

$\mathrm{NH}_{4} \mathrm{VO}_{3}$ from Fluka was used as a substrate. Decomposition process was carried out in dry air (Messer, Germany) containing 20,5\% vol. $\mathrm{O}_{2}$ rest $\mathrm{N}_{2}$. Impurities occurred in amounts: $\mathrm{H}_{2} \mathrm{O}<10$ vpm, $\mathrm{CO}_{2}<0,5 \mathrm{vpm}, \mathrm{NO}_{x}<0,1 \mathrm{vpm}$, hydrocarbons $<0,1 \mathrm{vpm}$. Thermogravimetric measurements were carried out on TG-DSC Q600 (TA Instruments) apparatus. Gaseous products of proceeding transitions were identified by mass spectrometry method. Pfeifer Vacuum ThermoStar GDS 301 apparatus was used. Solid products were identified by XRD method. X'Pert Pro apparatus from PANalytical with a copper X-ray tube with current voltage $35 \mathrm{kV}$ and intensity $40 \mathrm{~mA}$ was used. Spectra processing and analysis was performed using X'Pert HighScore 1.0 software with incorporated ICDD spectra library.

\subsection{Results}

During the TG-DSC measurements weighed amounts of the sample in the order of $20 \mathrm{mg}$ were used. The temperature of the sample, TG, DTG and HF functions, and mass spectra of gaseous products were registered in time. In all series the temperature of samples changed linearly in time. It was found that thermal decomposition of $\mathrm{NH}_{4} \mathrm{VO}_{3}$ in dry air proceeds in the three endothermic stages according to

$$
6 \mathrm{NH}_{4} \mathrm{VO}_{3} \rightarrow\left(\mathrm{NH}_{4}\right)_{3} \mathrm{~V}_{6} \mathrm{O}_{16} \rightarrow\left(\mathrm{NH}_{4}\right)_{2} \mathrm{~V}_{6} \mathrm{O}_{16} \rightarrow \mathrm{V}_{2} \mathrm{O}_{5}
$$


The theoretical, total mass loss of the sample equals $22,29 \mathrm{wt} \%$. The mass losses in the stages, referred to the initial mass of the sample, equal: $11,48 \mathrm{wt} \%$ in stage $\mathrm{I}, 4,404 \mathrm{wt} \%$ in stage II, and $6,66 \mathrm{wt} \%$ in stage III. The intermediate products (for control also the final product) were obtained under isothermal conditions, in the temperature ranges of their occurrence. As the final product $\mathrm{V}_{2} \mathrm{O}_{5}$ (ICDD card 85-0601), and as the second intermediate product $\left(\mathrm{NH}_{4}\right)_{2} \mathrm{~V}_{6} \mathrm{O}_{16}$ (ICDD card 79-205) were obtained. The intermediate product formed in step I was identified on the basis of the mass balance (there is no pattern of this compound in ICDD directory). In all the stages and at different heating rates of the samples evolved: $\mathrm{NH}_{3}, \mathrm{H}_{2} \mathrm{O}, \mathrm{NO}$ and $\mathrm{N}_{2} \mathrm{O}$ resulting from oxidation of $\mathrm{NH}_{3}$. In the gas phase $\mathrm{NO}_{2}$ did not occur. The results of this step of research are given in [19].

\subsubsection{Analysis of influence of sample heating rate on the course of the process}

The influence of sample heating rate on the course of the process was examined on the basis of the TGu , DTG and HF functions. The measurements were carried out at sample heating rates of: $1 ; 1,5 ; 2 ; 2,5 ; 3 ; 3,5 ; 4 ; 4,5 ; 5 ; 6 ; 7 ; 8$ and $10 \mathrm{~K} \mathrm{~min}^{-1}$. The isothermal measurements were carried out at the sample heating rate equal to $2 \mathrm{~K} \mathrm{~min}^{-1}$. Basing on the TG-DSC measurements the division of the process into stages was made and the conversion degrees for the stages were determined. There should be added that the data sets concerning conversion degrees, determined for the stages, are the basis for the description of process kinetics as in $[1,17,20-23]$.

\subsubsection{Analysis of TGu, DTG and HF charts}

The trajectories of TGu, DTG and HF plots are presented in separate figures. In Figure 1 TGu functions in temperature registered during the measurements are presented.

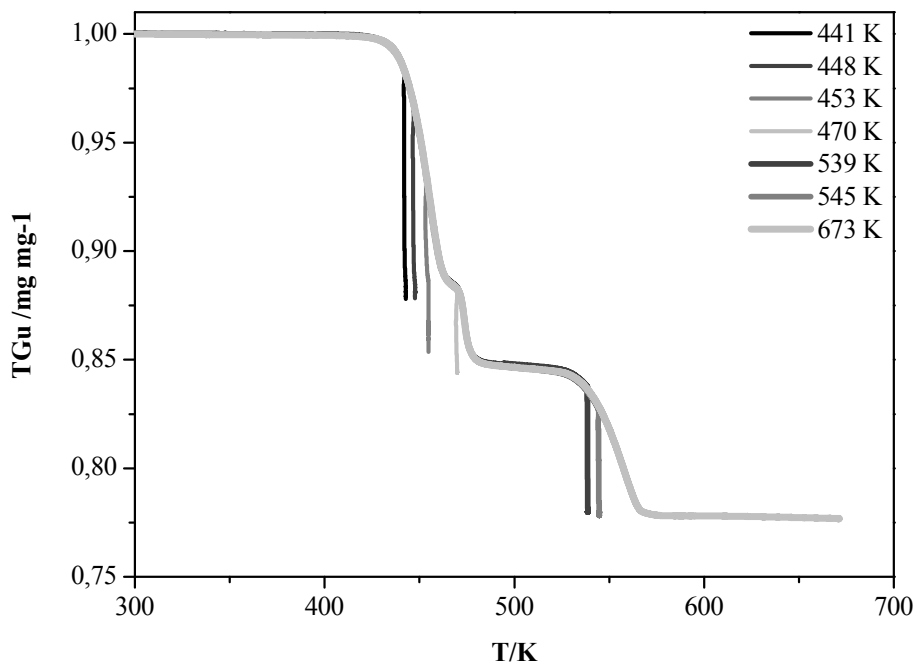

Figure 1. TGu functions in temperature. Decomposition of $\mathrm{NH}_{4} \mathrm{VO}_{3}$ in dry air [19]. 
The linear segments correspond to the isothermal conditions. The samples were heated isothermally until the stable mass has been reached (about $30 \mathrm{~min}$ ).

In case of the investigated process, under isothermal conditions, the results for the stage could by obtained only at a few temperatures, while at higher temperatures the results were obtained at high conversion degrees. For these reasons, the course of investigated process was not further examined under isothermal conditions.

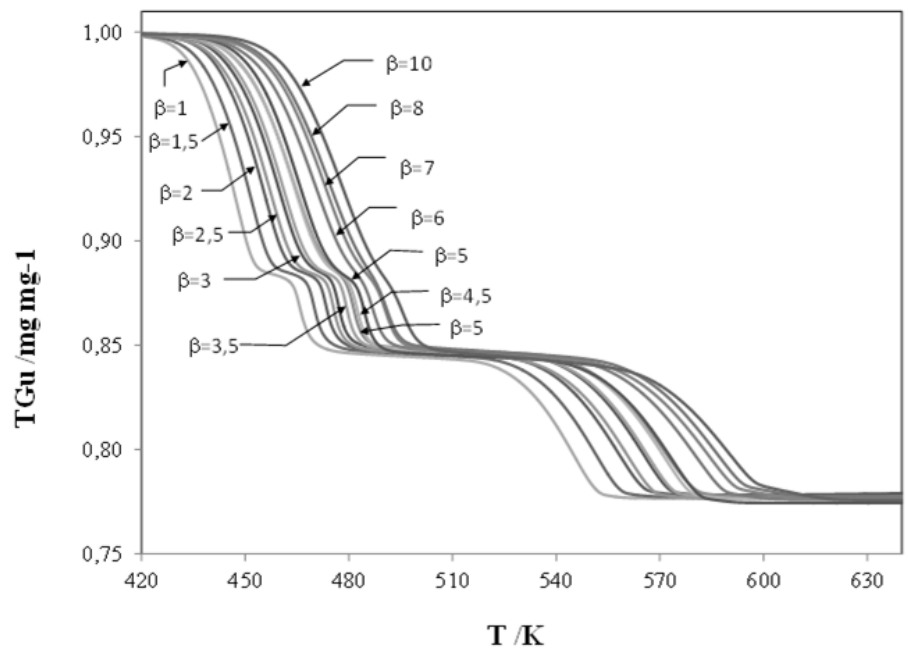

Figure 2. Plot of TGu functions in temperature. Decomposition of $\mathrm{NH}_{4} \mathrm{VO}_{3}$ in dry air [19].

In Figure 2 the plots of TGu function in temperature obtained under non-isothermal conditions are presented. The single curve is formed of about 20 thousand points. The determined TGu values should depend only on temperature and heating rate of the samples. This was confirmed by neural networks method in reference [24]. All the series were considered simultaneously. The computer software Statistica Neural Network was used. Figure 3 shows an example of DTG plots for selected heating rates of the samples.

It follows that at higher $\beta_{i}$ the temperature range $T_{\alpha=0} \div T_{\alpha=1}$. increases (Fig.3). The temperature range of the process in stage is an important parameter.

Along with the increase of sample heating rates the DTG function plots are shifted into the higher temperature range. It is also visible that at the higher sample heating rates stages I and II are overlapped to a larger extent, and the final segments of plots, corresponding to the stage III, are not monotonic. As mentioned before, this was attributed to the oxidation of formed earlier $\mathrm{V}_{2} \mathrm{O}_{5-\mathrm{x}}$ to $\mathrm{V}_{2} \mathrm{O}_{5}$. The $\mathrm{T}_{\mathrm{m}}$ temperatures corresponding to peaks of DTG function plots (necessary for Kissinger's method) have been determined. The results are listed in Table 1.

The values of $\alpha_{\mathrm{m}}$, for $\mathrm{T}_{\mathrm{m}}$ temperatures given in Table1 were retrieved from data sets of $\alpha(\mathrm{T})$. There are also given the temperature ranges, determined basing on DTG plots, for the stages. 


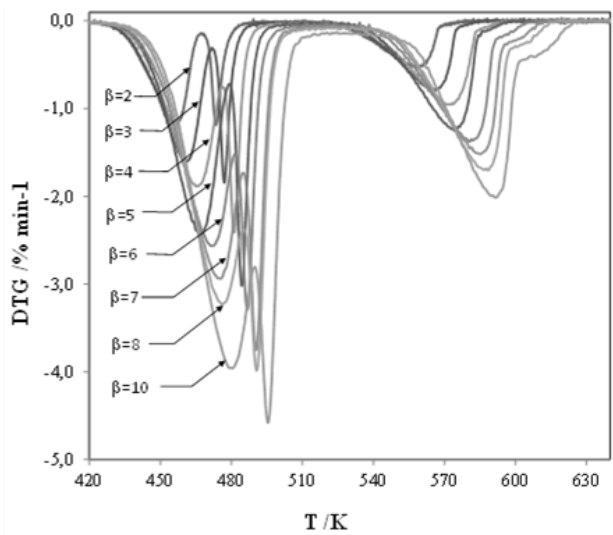

Figure 3. Plots of DTG function in temperature. Decomposition of $\mathrm{NH}_{4} \mathrm{VO}_{3}$ in dry air [19].

\begin{tabular}{|c|c|c|c|c|c|c|c|c|c|}
\hline \multirow{2}{*}{$\begin{array}{l}\beta \\
\mathrm{Kmin}^{-1}\end{array}$} & \multicolumn{3}{|c|}{ Stage I } & \multicolumn{3}{|c|}{ Stage II } & \multicolumn{3}{|c|}{ Stage III } \\
\hline & $\mathrm{T}_{\mathrm{m}} / \mathrm{K}$ & $\alpha_{\mathrm{m}}$ & $\Delta \mathrm{T} / \mathrm{K}$ & $\mathrm{T}_{\mathrm{m}} / \mathrm{K}$ & $\alpha_{\mathrm{m}}$ & $\Delta \mathrm{T} / \mathrm{K}$ & $\mathrm{T}_{\mathrm{m}} / \mathrm{K}$ & $\alpha_{\mathrm{m}}$ & $\Delta \mathrm{T} / \mathrm{K}$ \\
\hline 1 & 447,83 & 0,721 & $\begin{array}{c}410,75- \\
457,95\end{array}$ & 465,65 & 0,384 & $\begin{array}{c}457,95- \\
490,65\end{array}$ & 543,93 & 0,617 & $\begin{array}{c}509,25- \\
566,15\end{array}$ \\
\hline 1,5 & 452,62 & 0,742 & $\begin{array}{c}405,55- \\
462,85\end{array}$ & 469,87 & 0,415 & $\begin{array}{c}462,85- \\
489,45\end{array}$ & 550,38 & 0,653 & $\begin{array}{c}513,25- \\
572,15\end{array}$ \\
\hline 2 & 457,48 & 0,761 & $\begin{array}{c}413,15- \\
467,55\end{array}$ & 473,58 & 0,476 & $\begin{array}{c}467,55- \\
491,35\end{array}$ & 558,2 & 0,705 & $\begin{array}{c}516,25- \\
580,45\end{array}$ \\
\hline 2,5 & 458,06 & 0,698 & $\begin{array}{c}412,85- \\
469,65\end{array}$ & 475,6 & 0,443 & $\begin{array}{c}469,65- \\
494,65\end{array}$ & 560,65 & 0,701 & $\begin{array}{c}518,15- \\
583,45\end{array}$ \\
\hline 3 & 460,18 & 0,683 & $\begin{array}{c}415,65- \\
472,15\end{array}$ & 477,16 & 0,495 & $\begin{array}{c}472,15- \\
496,15\end{array}$ & 565,44 & 0,729 & $\begin{array}{c}522,95- \\
590,75\end{array}$ \\
\hline 3,5 & 462,25 & 0,703 & $\begin{array}{c}415,65- \\
474,15\end{array}$ & 479,51 & 0,474 & $\begin{array}{c}474,15- \\
497,15\end{array}$ & 567,21 & 0,737 & $\begin{array}{c}523,75- \\
590,75\end{array}$ \\
\hline 4 & 465,12 & 0,689 & $\begin{array}{c}413,25- \\
476,15\end{array}$ & 481,41 & 0,517 & $\begin{array}{c}476,15- \\
503,15\end{array}$ & 572,81 & 0,744 & $\begin{array}{c}526,55- \\
596,75\end{array}$ \\
\hline 4,5 & 465,32 & 0,689 & $\begin{array}{c}417,25- \\
476,95 \\
\end{array}$ & 481,9 & 0,38 & $\begin{array}{c}476,95- \\
500,35 \\
\end{array}$ & 572,17 & 0,743 & $\begin{array}{c}526,15- \\
595,15 \\
\end{array}$ \\
\hline 5 & 467,29 & 0,714 & $\begin{array}{c}418,45- \\
479,35\end{array}$ & & & & 574,3 & 0,736 & $\begin{array}{l}530,45- \\
597,95\end{array}$ \\
\hline 6 & 471,44 & 0,698 & $\begin{array}{c}416,45- \\
481,85\end{array}$ & & & & 580,7 & 0,719 & $\begin{array}{c}533,45- \\
609,25\end{array}$ \\
\hline 7 & 475,68 & 0,741 & $\begin{array}{c}417,15- \\
485,25\end{array}$ & & & & 588,2 & 0,83 & $\begin{array}{c}537,85- \\
614,15\end{array}$ \\
\hline 8 & 476,22 & 0,71 & $\begin{array}{c}421,65- \\
485,25\end{array}$ & & & & 587,06 & 0,723 & $\begin{array}{c}536,25- \\
620,75 \\
\end{array}$ \\
\hline 10 & 480,09 & 0,716 & $\begin{array}{c}423,15- \\
490,15\end{array}$ & & & & 591,89 & 0,73 & $\begin{array}{c}538,85- \\
625,35\end{array}$ \\
\hline
\end{tabular}

Table 1. List of data for Kissinger's method. Thermal decomposition of $\mathrm{NH}_{4} \mathrm{VO}_{3}$ in dry air. 
In Figure 4 the HF function in temperature has been presented for selected example values of $\beta$.

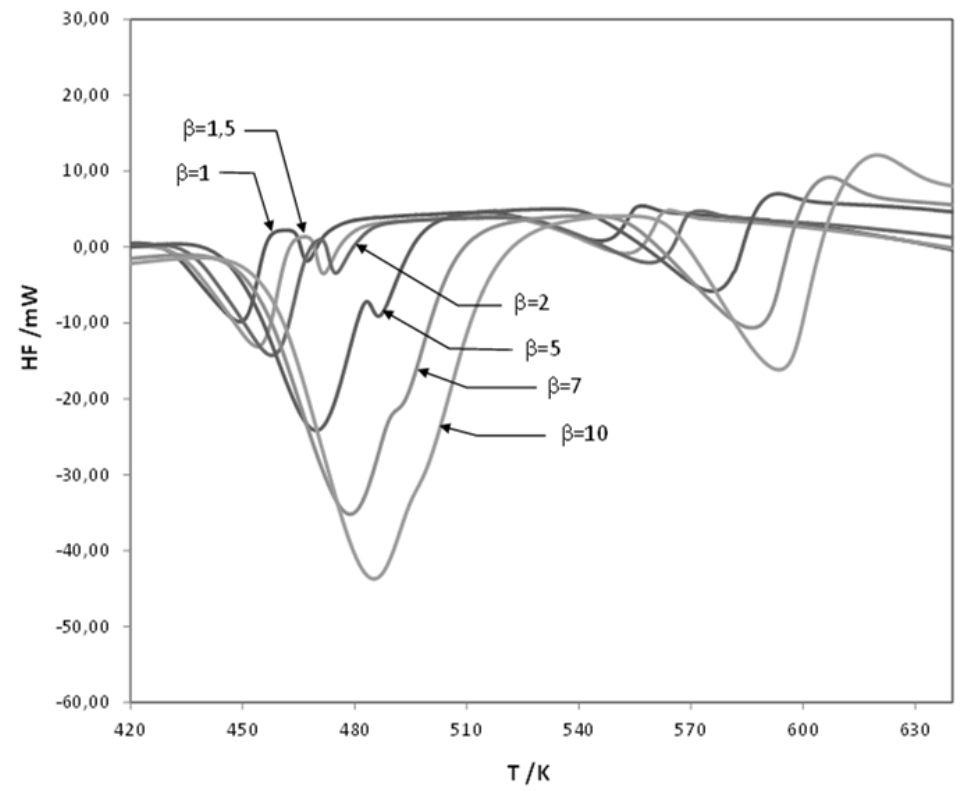

Figure 4. Plots of $\mathrm{HF}$ functions in temperature. Decomposition of $\mathrm{NH}_{4} \mathrm{VO}_{3}$ in dry air.

It is visible from the course of HF plots that in the case there are three endothermic stages referred to the $\mathrm{NH}_{4} \mathrm{VO}_{3}$ decomposition. The HF plots end with the exothermic transition attributed to the oxidation of small amount of $\mathrm{V}_{2} \mathrm{O}_{5-\mathrm{x}}$ to $\mathrm{V}_{2} \mathrm{O}_{5}$. Along with the increase of sample heating rate stages I and II overlap. Peaks of HF function are shifted, with respect to the DTG peaks, by a few degrees into the range of higher temperature. There should be added that $\mathrm{NH}_{3}, \mathrm{H}_{2} \mathrm{O}, \mathrm{NO}$ and $\mathrm{N}_{2} \mathrm{O}$ evolved in all the stages, also at higher simple heating rates.

\subsubsection{Analysis of $\alpha(T)$ plots for determined stages}

The conversion degrees for stages were calculated from the following formula

$$
\alpha(T)=\frac{m_{0}-m}{m_{0}-m_{k}}
$$

The data concerning the TGu function were the basis for calculations. During the division of the process into stages also DTG and HF plots were taken into account [22-24].

In Figure 5 the results obtained for the stages are presented. One curve was formed of a few thousand points. 

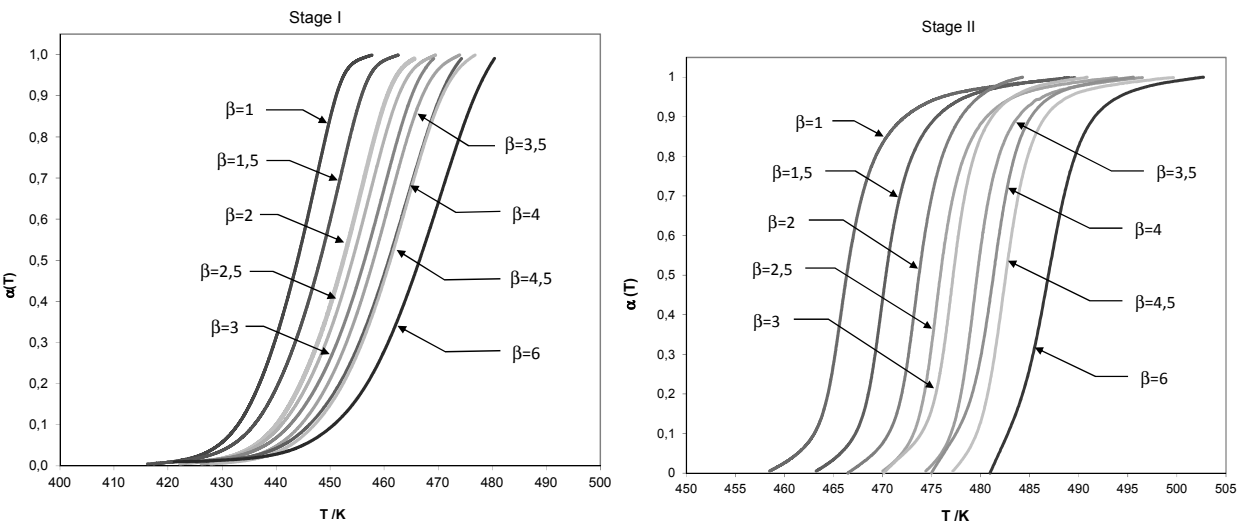

Stage III

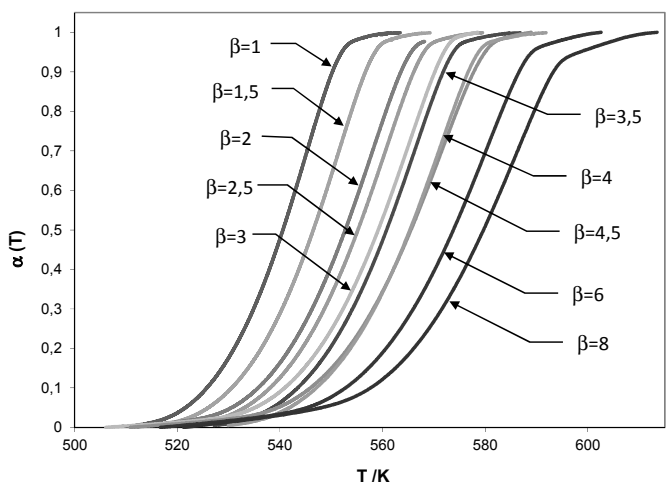

Figure 5. Plots of $\alpha(\mathrm{T})$ depending on temperature for the stages. Thermal decomposition of $\mathrm{NH}_{4} \mathrm{VO}_{3}$ in dry air.

\subsection{Result analysis}

\subsubsection{Kissinger's method} In Figure 6 the plots of $\ln \left(\frac{\beta_{i}}{T_{m, i}^{2}}\right) \div \frac{1000}{T_{m, i}}$ for the stages, obtained on the basis of the data from
Table 1 , are presented.

The parameters for Kissinger's equation (11) were calculated by linear regression method. The computer software Statistica 6.0 was used. The results are listed in Table 2.

\begin{tabular}{|c|c|c|c|c|c|c|c|}
\hline Stage & $\mathrm{E} \mathrm{kJ} \mathrm{mol}^{-1}$ & $\mathrm{~B}^{*}$ & $\mathrm{Af}^{\prime}\left(\alpha_{\mathrm{m}}\right) 1 \mathrm{~min}^{-1}$ & $\mathrm{r}_{\mathrm{p}}$ & model & $-\mathrm{f}^{\prime}\left(\alpha_{\mathrm{m}}\right)$ & $\mathrm{A} 1 \mathrm{~min}^{-1}$ \\
\hline I & 117,66 & 19,496 & $4,133 \mathrm{E} 12$ & 0,979 & $\mathrm{~A} 2$ & 2,476 & $1,669 \mathrm{E} 12$ \\
\hline II & 164,48 & 30,178 & $2,37 \mathrm{E} 17$ & 0,989 & $\mathrm{~A} 4$ & 6,762 & $3,504 \mathrm{E} 16$ \\
\hline III & 113,75 & 12,623 & $4,137 \mathrm{E} 9$ & 0,985 & $\mathrm{~A} 2$ & 2,596 & $1,594 \mathrm{E} 9$ \\
\hline
\end{tabular}

Table 2. List of the results calculated by Kissinger's method. Thermal decomposition of $\mathrm{NH}_{4} \mathrm{VO}_{3}$ in dry air. * constant in Kissinger's equation (11) 


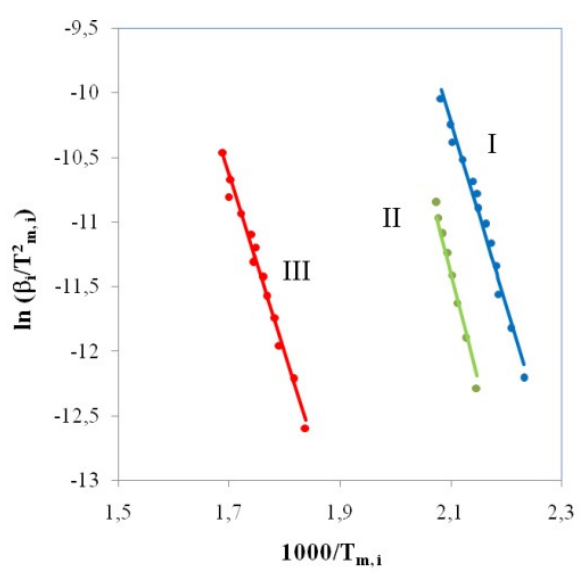

Figure 6. Plots of $\ln \left(\frac{\beta_{i}}{T_{m, i}^{2}}\right) \div \frac{1000}{T_{m, i}}$ for the stages. Thermal decomposition of $\mathrm{NH}_{4} \mathrm{VO}_{3}$ in dry air.

The kinetic models for the stages were determined analyzing the courses of the function

$$
\mathrm{Y}(\mathrm{T})=\frac{A f^{\prime}\left(\alpha_{m}\right)}{\beta_{i}} \int_{T_{\alpha=0,01}}^{T_{\alpha=0.99}} \exp \left(-\frac{E}{R T}\right) d T .
$$

There should be added, that the values of $\alpha_{\mathrm{m}}$ determined for the stage, changed marginally for different $\beta$. Therefore, there could be assumed that $f^{\prime}\left(\alpha_{m}\right) \approx$ const . In figure 7 plots of

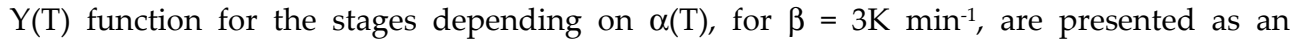
example.

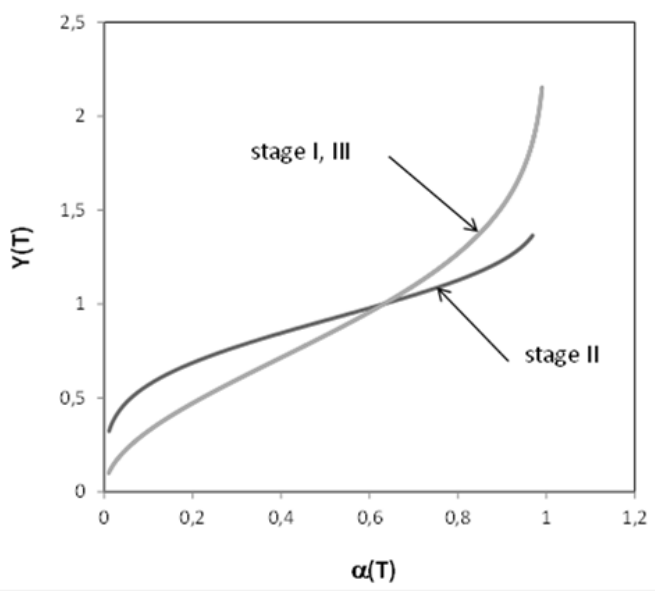

Figure 7. Plots of $Y(T)$ function for the stages depending on $\alpha(T)$ for $\beta=3 \mathrm{~K} \mathrm{~min} \mathrm{~m}^{-1}$. Thermal decomposition of $\mathrm{NH}_{4} \mathrm{VO}_{3}$ in dry air. 
For the stages I, III the most consistent with experimental data, of the tested models, was the A2 model.

$$
\begin{gathered}
g(\alpha)=[-\ln (1-\alpha)]^{\frac{1}{2}} \\
f(\alpha)=2(1-\alpha)[-\ln (1-\alpha)]^{\frac{1}{2}} \\
f^{\prime}\left(\alpha_{m}\right)=-2\left[-\ln \left(1-\alpha_{m}\right)\right]^{\frac{1}{2}}-\frac{1-\alpha_{m}}{\alpha_{m}\left[-\ln \left(1-\alpha_{m}\right)\right]^{\frac{1}{2}}}
\end{gathered}
$$

Whereas for stage II this was the A4 model

$$
\begin{gathered}
g(\alpha)=[-\ln (1-\alpha)]^{\frac{1}{4}} \\
f(\alpha)=4(1-\alpha)[-\ln (1-\alpha)]^{\frac{3}{4}} \\
f^{\prime}\left(\alpha_{m}\right)=-4\left[-\ln \left(1-\alpha_{m}\right)\right]^{\frac{3}{4}}-\frac{3\left(1-\alpha_{m}\right)}{\alpha_{m}\left[-\ln \left(1-\alpha_{m}\right)\right]^{\frac{1}{4}}}
\end{gathered}
$$

The selection of the model was confirmed making calculations by Coats - Redfern method. The selected models and calculated values of $f^{\prime}\left(\alpha_{m}\right)$ are given in Table 2.

\subsubsection{Isoconversional method}

The basis for calculations by this method were dependencies $\alpha(T)$ determined for the stages at different heating rates of the samples (Fig. 5). First, the activation energies were calculated for $\alpha_{\mathrm{m}, \mathrm{i}}$ corresponding to the inflection points of $\alpha(\mathrm{T})$ curves (average values of $\alpha_{\mathrm{m}}$ given in Table 1). In this case, formula (21) should take the form of equation (11). In Figure 8 the obtained plots of $\ln \left(\frac{\beta_{i}}{T_{\alpha_{m}^{\prime}, i}^{2}}\right) \div \frac{1000}{T_{\alpha_{m}, i}}$ are presented.

The results of calculations are given in Table 3. This method is less accurate than the Kissinger's method

\begin{tabular}{|l|l|l|l|l|}
\hline Stage & $\alpha_{\mathrm{m}}$ & $\mathrm{E} / \mathrm{kJmol}^{-1}$ & $\mathrm{~B}^{*}$ & $\mathrm{r}_{\mathrm{p}}$ \\
\hline I & 0,713 & 117,3 & 19,401 & 0,989 \\
\hline II & 0,460 & 148,2 & 26,05 & 0,987 \\
\hline III & 0,721 & 122,3 & 14,426 & 0,988 \\
\hline
\end{tabular}

Table 3. List of the results of activation energies calculations by isoconversional method for the inflection points of $\alpha(\mathrm{T})$ curves. $^{*}$ ) constant in equation (21). 


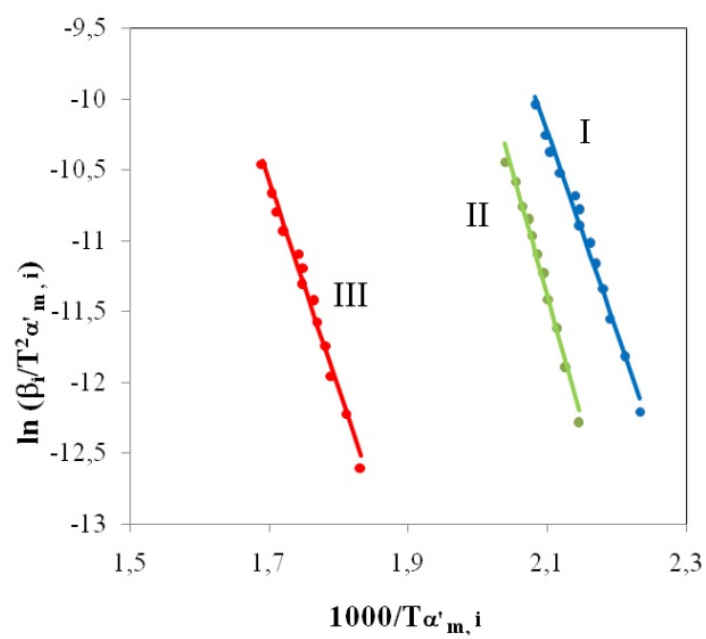

Figure 8. Plots of $\ln \left(\frac{\beta_{i}}{T_{\alpha_{m}, i}^{2}}\right) \div \frac{1000}{T_{\alpha_{m}, i}}$ for the stages. Isoconversional method. Conversion degrees equal to $\alpha_{\mathrm{m}, \mathrm{i}}$.

The calculations for other values of conversion degree were also performed. Should be noted that $\alpha(T)$ tend asymptotically to the limit values. In these ranges $T_{\alpha, i}$ could not be determined with sufficient accuracy. Therefore, the calculation was performed $0,1<\alpha<0,90$.

The plots of $\ln \left(\frac{\beta_{i}}{T_{\alpha, i}^{2}}\right) \div \frac{1000}{T_{\alpha, i}}$ for the stages are shown in Figure 9.

The values of activation energies calculated by the isokinetic method are given in Table 4 .

\begin{tabular}{|c|c|c|c|c|c|c|c|c|c|}
\hline \multirow{2}{*}{$\alpha_{\mathrm{i}}$} & \multicolumn{3}{|c|}{ Stage I } & \multicolumn{3}{c|}{ Stage II } \\
\cline { 2 - 10 } & $\begin{array}{c}\mathrm{E} \mathrm{mol}^{-1} \\
0\end{array}$ & $\mathrm{~B}^{*}$ & $\mathrm{r}_{\mathrm{p}}$ & $\begin{array}{c}\mathrm{E} \\
\mathrm{kJ} \mathrm{mol}^{-1}\end{array}$ & $\mathrm{~B}^{*}$ & $\mathrm{r}_{\mathrm{p}}$ & $\begin{array}{c}\mathrm{E} \\
\mathrm{kJ} \mathrm{mol}^{-1}\end{array}$ & $\mathrm{~B}^{*}$ & $\mathrm{r}_{\mathrm{p}}$ \\
\hline 0,1 & 140,45 & 27,00 & 0,986 & 163,02 & 30,083 & 0,996 & 147,58 & 21,299 & 0,991 \\
\hline 0,2 & 131,69 & 24,303 & 0,988 & 161,22 & 29,493 & 0,998 & 137,71 & 18,709 & 0,990 \\
\hline 0,3 & 128,45 & 23,06 & 0,991 & 158,71 & 28,788 & 0,992 & 126,45 & 16,012 & 0,991 \\
\hline 0,4 & 125,65 & 22,099 & 0,995 & 155,72 & 27,987 & 0,994 & 130,05 & 16,577 & 0,989 \\
\hline 0,5 & 123,13 & 21,256 & 0,999 & 156,50 & 28,187 & 0,994 & 127,46 & 15,849 & 0,986 \\
\hline 0,7 & 120,29 & 20,351 & 0,989 & 154,54 & 27,58 & 0,989 & 125,48 & 15,276 & 0,987 \\
\hline 0,8 & 117,56 & 19,489 & 0,988 & 156,70 & 28,065 & 0,985 & 122,94 & 14,597 & 0,985 \\
\hline 0,9 & 112,38 & 17,69 & 0,988 & 158,2 & 28,365 & 0,982 & 121,83 & 14,227 & 0,987 \\
\hline
\end{tabular}

Table 4. The activation energies calculated for the stages by the isoconversional method. Thermal decomposition of $\mathrm{NH}_{4} \mathrm{VO}_{3}$ in dry air. ${ }^{*}$ constant in equation (21) 
In the case of investigated process, the E for the stages I and III (asymmetric plots of DTG and HF), changed continuously along with the change of conversion degree. In the case of stage II (symmetric plots of DTG and HF) E was practically constant, similar to that determined by Kissinger's method. That is the isokinetic method compensates the impact of $\beta_{i}$ on the course of the process by changing the activation energy. Theoretically [25] much more interesting is the possibility to compensate the impact of $\beta_{\mathrm{i}}$, at a constant activation energy, with use of temperature ranges $T_{\alpha=0} \div T_{\alpha=1}$, the values determined experimentally.

Stage I

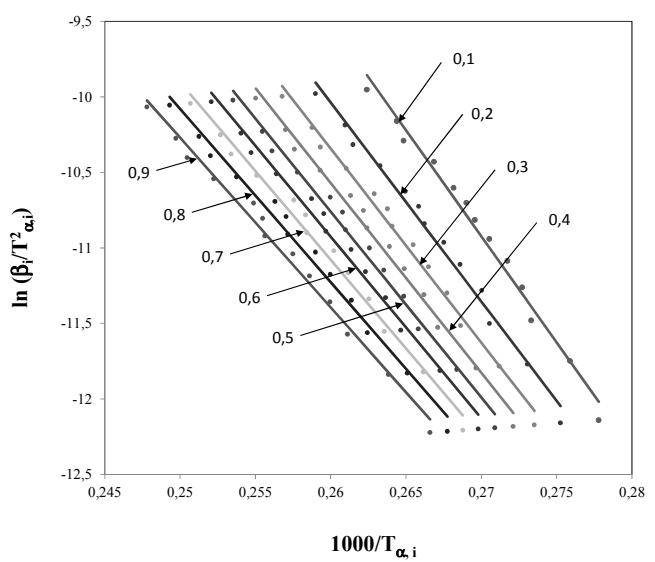

Stage II

Stage III
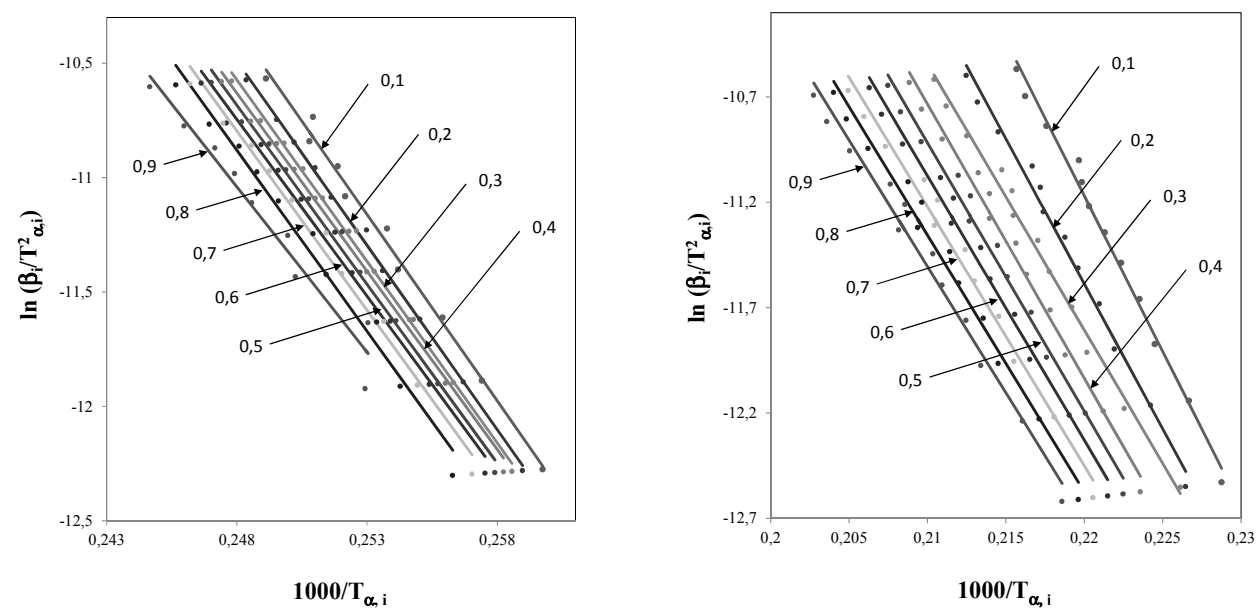

Figure 9. Plots of $\ln \left(\frac{\beta_{i}}{T_{\alpha, i}^{2}}\right) \div \frac{1000}{T_{\alpha, i}}$ for the stages. Thermal decomposition of $\mathrm{NH}_{4} \mathrm{VO}_{3}$ in dry air. 


\subsubsection{Coats - Redfern method}

During the calculations by this method the sets of $\alpha(\mathrm{T})$ presented in Figure 5 were also used.

The activation energies E, determined for the stages by Kissinger's method (for $\alpha_{\mathrm{m}}$ values belonging to the sets of $\alpha(T))$, were taken as the base values. The plots of $\ln \left[\frac{g(\alpha)}{T^{2}}\right] \div \frac{E}{R T}$ were constructed. Among the known kinetic models the ones the most consistent with the experimental data were selected; for stages I and III model A2, and for stage II model A4. For the selected model and different $\beta_{i}$ the values of the coefficient $A$ were calculated for the stage in the following manner. First $\mathrm{Z}(\mathrm{T})$ was calculated from the formula

$$
Z(T)=\ln \left[\frac{A R}{\beta E}\left(1-\frac{2 R T_{m}}{E}\right)\right]=\ln \left[\frac{g(\alpha)}{T^{2}}\right]+\frac{E}{R T}
$$

Then $\ln \mathrm{A}$ was calculated according to

$$
\ln A=Z(T)+\ln \left[\frac{\beta E}{R\left(1-\frac{2 R T_{m}}{E}\right)}\right]
$$

The calculations of $Z(T)$ were performed for the range $0,01 \leq \alpha \leq 0,99$. The values of $T_{m}$ and the temperature ranges for the stages are given in Table 1 . However the calculated values of A are given in Table 5. For all the stages the obtained values of coefficient A were higher than the values determined by Kissinger's method. There should be added that the proportion between the values was remained.

Using average values of A the activation energies were tested. The criterion was the best conformity of trajectories of $\alpha(\mathrm{T})$ plots, calculated and determined experimentally, in the whole range. The conversion degrees were calculated as follows. First $g(\alpha)$ was calculated from the formula

$$
g(\alpha)=T^{2} \exp [F(T)]
$$

Formula (32) is suitable for different models. Whereas the method of calculating conversion degrees depends on the form of kinetic model. For example, for model A2

$$
g(\alpha)=[-\ln (1-\alpha)]^{\frac{1}{2}}
$$

thus

$$
\alpha=1-\exp \left\{-[g(\alpha)]^{2}\right\}
$$


The values of activation energy calculated in this way are given in Table 5.

\begin{tabular}{|l|c|c|c|c|c|c|c|c|c|}
\hline \multirow{2}{*}{$\begin{array}{l}\beta \\
\text { K min }\end{array}$} & \multicolumn{2}{|c|}{ Stage I; A2; E=117,66 } & \multicolumn{2}{c|}{ Stage II; A4; E=164,48 } & \multicolumn{3}{c|}{ Stage III; A2; E=113,75 } \\
\cline { 2 - 11 } & $\Delta Z(\mathrm{~T})$ & $\begin{array}{c}\mathrm{A} \mathrm{E12} \\
\mathrm{min}^{-1}\end{array}$ & $\begin{array}{c}\mathrm{E}^{*} \\
\mathrm{~kJ} \mathrm{~mol}^{-1}\end{array}$ & $\Delta \mathrm{Z}(\mathrm{T})$ & $\begin{array}{c}\mathrm{A} \mathrm{E} 17 \\
\mathrm{~min}^{-1}\end{array}$ & $\begin{array}{c}\mathrm{E}^{*} \\
\mathrm{~kJ} \mathrm{~mol}^{-1}\end{array}$ & $\Delta \mathrm{Z}(\mathrm{T})$ & $\begin{array}{c}\text { A E9 } \\
\mathrm{min}^{-1}\end{array}$ & $\begin{array}{c}\mathrm{E}^{*} \\
\mathrm{~kJ} \mathrm{~mol}^{-1}\end{array}$ \\
\hline 1 & 19,81 & 5,91 & 114,10 & 29,98 & 1,468 & 157,48 & 12,72 & 4,97 & 110,2 \\
\hline 1,5 & 19,58 & 7,23 & 114,36 & 29,34 & 1,721 & 157,85 & 12,46 & 5,73 & 110,5 \\
\hline 2 & 19,22 & 6,71 & 114,56 & 29,31 & 2,227 & - & - & - & - \\
\hline 2,5 & 19,12 & 7,61 & 114,60 & 28,85 & 1,436 & 157,00 & 12,06 & 6,52 & 110,6 \\
\hline 3 & 19,11 & 9,02 & 115,06 & 28,87 & 2,150 & 158,20 & 12,05 & 7,54 & 111,1 \\
\hline 3,5 & 18,82 & 7,85 & 114,56 & 28,57 & 1,860 & 157,90 & 11,76 & 6,70 & 110,5 \\
\hline 4 & 18,83 & 9,15 & 115,26 & 28,51 & 1,908 & 158,50 & 11,76 & 7,59 & 111,5 \\
\hline 4,5 & 18,61 & 8,27 & 114,56 & 28,31 & 1,845 & 157,88 & 11,57 & 7,10 & 110,5 \\
\hline 5 & 18,57 & 8,84 & 114,76 & 28,34 & 2,113 & 158,80 & 11,50 & 7,31 & 110,6 \\
\hline 6 & 18,41 & 8,99 & 115,16 & 27,98 & 1,770 & 158,10 & 11,33 & 7,48 & 111,1 \\
\hline 7 & 18,24 & 8,85 & 115,36 & 27,81 & 1,742 & 158,90 & 11,19 & 7,56 & 111,3 \\
\hline
\end{tabular}

Table 5. The kinetic parameters obtained by Coats-Redfern method. Thermal decomposition of $\mathrm{NH}_{4} \mathrm{VO}_{3}$ in dry air.

The parameters $\mathrm{A}$ and $\mathrm{E}$ determined by this method for different $\beta_{\mathrm{i}}$ remain nearly constant.

The corrected activation energies are slightly lower than the ones determined by Kissinger's method; in the case of stage II they are practically equal to the values calculated by isokinetic method. The result is interesting because it shows that the activation energy determined by Kissinger's method can be regarded as representative for the whole set of $\alpha(\mathrm{T})$ related to the stage. It should also be emphasized that determining the triad of $g(\alpha)$, A and $\mathrm{E}$ directly from the Coats-Redfern equation, usually the good results are not obtained $[1,21,24]$. That is it is a matter of calculation methods, and not of the Coats-Redfern equation.

Using the kinetic parameters given in table 5 the verifying calculations were performed. For the selected $\beta_{i}$ the trajectories of $\alpha(T)$ and $r(\alpha, T)$ functions were determined. The process rate was calculated from the formula

$$
r(\alpha, T)=A \exp \left(-\frac{E}{R T}\right) f(\alpha)
$$

While calculating $f(\alpha)$ the values of $\alpha(T)$ obtained from the Coats-Redfern equation (formulas (32)-(34)) were used. In Figure 10 the results obtained for stage I and II ( $\beta=2,4$ and $6 \mathrm{~K} \mathrm{~min}^{-1}$ ) are presented as an example. 

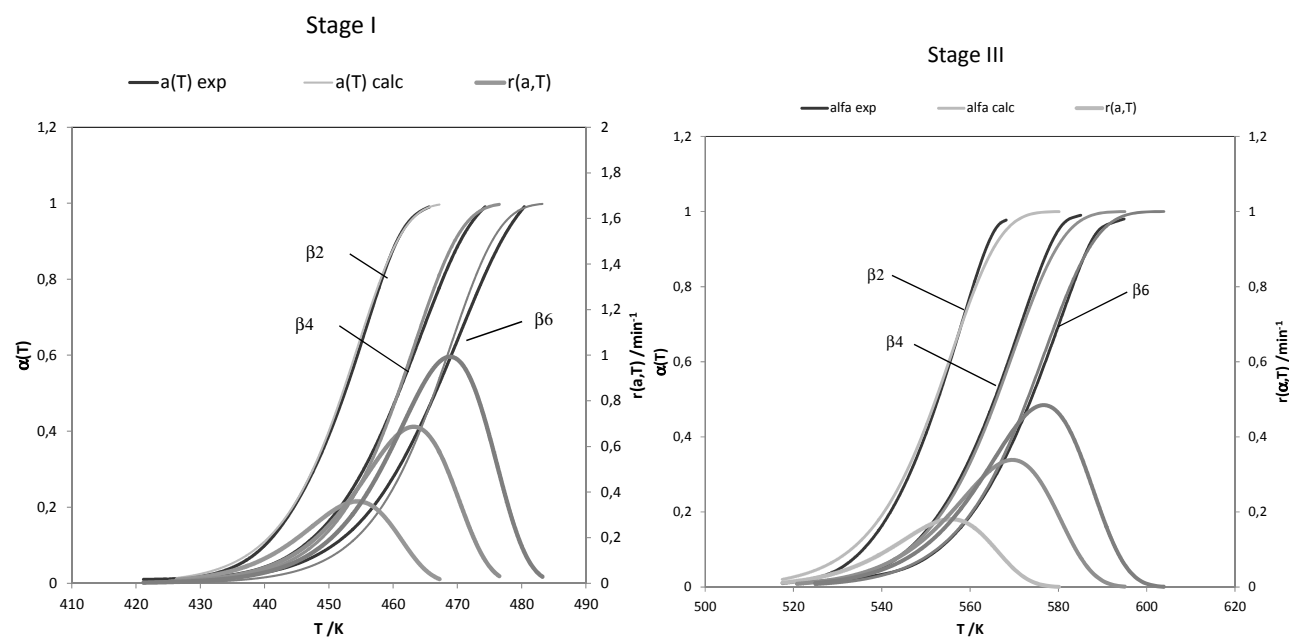

Figure 10. Plots of $\alpha(\mathrm{T})$ and $\mathrm{r}(\mathrm{T}, \alpha)$ for the stage I and III. Thermal decomposition of $\mathrm{NH}_{4} \mathrm{VO}_{3}$ in dry air.

The results are fairly well consistent with the experimental data; at the experimentally determined temperature ranges the process rates change from zero for $\alpha(T)=0$, reaching the maximum values at the points of inflection of $\alpha(\mathrm{T})$ curves, and then decrease to zero at $\alpha(T) \rightarrow 0$. The obtained results show that in our study Coats-Redfern equation was of great importance. Due to the analytical form it is also easy to use in the calculations of the kinetics of heterophase non-catalytic processes.

\section{Heat treatment of $\mathrm{TiCx} / \mathrm{C}$. Carbonisation of $\mathrm{nc}-\mathrm{TiCx}$}

Manufacturing, storage and use of $\mathrm{nc}-\mathrm{TiC}$ in form of powder for sintering or co-deposition processes involves the possibility of occurrence of free carbon in the system. Carbon can be a by-product of the synthesis process (pyrolysis of hydrocarbons) and remain in equilibrium in the $\mathrm{TiC}-\mathrm{C}$ system or be the product of oxidation of $\mathrm{TiC}$ in the air according to the mechanism proposed by Schimada [26], whereby the oxygen dissolves in the carbide and the layer containing oxycarbides is formed.

$$
\mathrm{TiC}+(3 / 2) \times \mathrm{O}_{2} \rightarrow \mathrm{TiC}_{1-\mathrm{x}} \mathrm{O}_{\mathrm{x}}+\mathrm{CO}_{2}
$$

In second stage, in the layer amorphous $\mathrm{TiO}_{2}$ is formed and elemental carbon is produced [27-31]

$$
\mathrm{TiC}_{1-\mathrm{x}} \mathrm{O}_{\mathrm{x}}+(1-\mathrm{x} / 2) \mathrm{O}_{2} \rightarrow \mathrm{TiO}_{2}+(1-\mathrm{x}) \mathrm{C}
$$

The produced carbon changes the state of the surface of TiC particles. A low oxygen content is the most important prerequisite for high sintering activity of the nanocrystalline $\mathrm{TiC}$ powders, especially in the sintering processes, synthesis of the nanocomposites for example nc-TiC in metallic matrices. 
In the manufacturing of nanomaterials by sol-gel method the second, high temperature, i.e. at temperatures above $1400 \mathrm{~K}$, stage is essential. The first stage of this method is the sol-gel technique. This stage is carried out at lower temperature. The intermediate product of

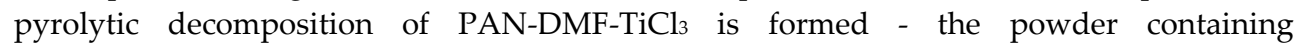
nanocrystalline $\mathrm{TiCx}$ in carbon matrix [6]. Nanocrystallites of titanium carbide are characterized by high fraction of lattice defects, i.e., vacant carbon sites, presence of oxygen and/or nitrogen. In the second stage carbonisation and purification of $\mathrm{TiC}_{\mathrm{x}} / \mathrm{C}$ composite in argon takes place. It is essential to obtain the materials with high values of the C/Ti ratio, while maintaining the proper, nanometric grain size, in order to obtain the most favourable properties such as hardness and oxidation resistance. The selection of parameters meeting these requirements is difficult.

There was assumed that the good basis are kinetic studies. They allow to determine the intermediate and final products, distinguish the stages of the process, determine the temperature ranges of their courses and obtain a quantitative description.

The kinetic measurements were carried out using TG-DSC-MS technique. Nanoparticles size, lattice parameter, chemical and phase composition before and after heat-treatment were determined with the following techniques: XRD (Philips PW3040/x0 X'Pert Pro), HRTEM (JEM 3010), SEM (JEOL JSM 6100), EDX (Oxford Instruments, ISIS 300), XPS (SIA 100 Cameca), total carbon measurement (MULTI EA2000, AnalyticJena), and the presence of free carbon was estimated by Raman Spectroscopy. The measurements were carried out under non-isothermal and isothermal conditions. The advantage of this method is the possibility of continuous registration of measured values and use of small weighed amounts of samples during measurements. The procedure is illustrated at the example of heat treatment in argon of the nanocomposite powder containing $\mathrm{nc}^{-\mathrm{TiC}} \mathrm{x}$ $(x \leq 0.7)$ in carbon matrix obtained by sol-gel method. The method ensures maintaining the small size of crystallites, by physically limiting the volume available for their growth, and the matrix prevents agglomeration of particles and oxidation during storage and transport.

At a certain temperature range, and under certain conditions, the reaction of carbonisation is possible

$$
\mathrm{TiC}_{\mathrm{x}}+\mathrm{yC} \rightarrow \mathrm{TiC}_{\mathrm{x}+\mathrm{y}}
$$

Heating of the samples in an argon atmosphere can lead to the growth of crystallites. The aim of this study was to develop conditions for annealing of the composite, under which, as a result of carbonisation, $\mathrm{TiC}_{\mathrm{x}}$ reaches a high stoichiometric composition, i.e. $\mathrm{x}>0.8$, at the minimal growth of crystallites. Obtaining such optimal material properties can be controlled by selecting the appropriate temperature and rate of the process.

The thermogravimetric measurements were carried out at sample heating rates of 10, 20, and $50 \mathrm{Kmin}^{-1}$. The mass of the samples were ca. $40 \mathrm{mg}$. During the measurements the samples were heated up to $1473,1573,1673$ and $1773 \mathrm{~K}$. These temperature values correspond to the isothermal conditions. The samples were heated under isothermal 
conditions for 6 h. High-purity argon 'Alphagaz 2 Ar' from Air Liquide $\left(\mathrm{H}_{2} \mathrm{O} \backslash \mathrm{ppm} / \mathrm{mol}\right.$, $\mathrm{O}_{2} \backslash 0.1 \mathrm{ppm} / \mathrm{mol}, \mathrm{C}_{\mathrm{n}} \mathrm{H}_{\mathrm{m}} \backslash 0.1 \mathrm{ppm} / \mathrm{mol}, \mathrm{CO} \backslash 0.1 \mathrm{ppm} / \mathrm{mol}, \mathrm{CO}_{2} \backslash 0.1 \mathrm{ppm} / \mathrm{mol}, \mathrm{H}_{2} \backslash 0.1$ $\mathrm{ppm} / \mathrm{mol}$ ) was used during experiments. With regard to reactivity of $\mathrm{O}_{2}$ the special attention during measurements was given to possibility of oxidation of components of the system during the process run. Argon purge flow rate during measurements was set at 100 $\mathrm{cm}^{3} / \mathrm{min}$. The part of the results in works $[17,32]$ were presented. Below the complete analysis description were introduced.

\subsection{Kinetic analysis}

The kinetic description of the process was based of thermogravimetric measurements. The results of the measurements are presented on the plots of sample temperature, TG, DTG and HF function dependencies on time (Fig. 11).

Initially the measurements were carried out under non-isothermal conditions at a linear change in sample temperature, then at the transitional regime, and finally under isothermal conditions (Fig.11a). It should be added that these results were the basis of the description of the process. The theory of kinetics under non-isothermal conditions require that this function depends only on the sample heating rate and temperature. The results were evaluated by neural networks method. Neural networks, used to analyze the non-isothermal measurements, were previously described in [20-23]. The TGu function was the described (dependent) variable, and the sample heating rate and temperature were the describing (indepedent) variables. All the measurement series were examined simultaneously. The received network was GRNN 2/11310. Statistical analysis of this network is given in Table 6.

\begin{tabular}{|l|l|l|l|}
\hline Parameter & $\mathrm{Tr}$ & $\mathrm{Ve}$ & $\mathrm{Te}$ \\
\hline S.D. Ratio & 0.01716 & 0.01926 & 0.01734 \\
\hline Correlation & 0.999874 & 0.999845 & 0.99987 \\
\hline
\end{tabular}

Table 6. Statistical estimation of GRNN 2/11310 network

In columns 2, 3, 4 the statistical evaluation of training (Tr), verification (Ve) and testing (Te) subset is listed.

A high accuracy was obtained. The TG dependencies determined experimentally could have been used in kinetic calculations.

The essential operation is the division of the process into stages. Basing on the presented measurement results four stages of the process were identified (Fig. 12). In the endothermic stage I, proceeding with a weight loss, the release and desorption of volatile products, contained in the samples after the first stage, occurred. In the exothermic, second stage, marked with the symbol II, proceeding with a samples weight gain, the oxidation of noncarbonised $\mathrm{nc}^{-\mathrm{TiC}} \mathrm{x} / \mathrm{C}$ by oxygen present in trace amounts in argon occurred. In the endothermic third stage, labeled by III, simultaneously proceeded the pyrolysis of organic 
admixtures and carbonisation of $\mathrm{nc}-\mathrm{TiC} \times \mathrm{C}$. The pyrolysis and carbonisation were treated as concurrent reactions. Stage IV (exothermic) proceeded with sample weight gain. It concerns the oxidation of carbonised nc-TiC with oxygen contained in argon. The process proceeded at temperature above $1573 \mathrm{~K}$.

a)

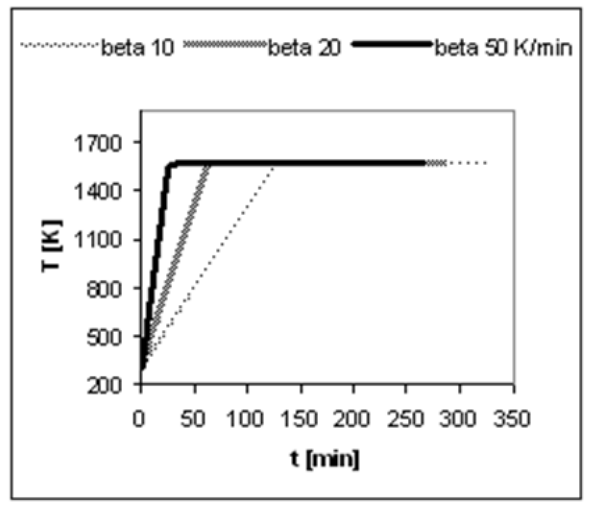

c)

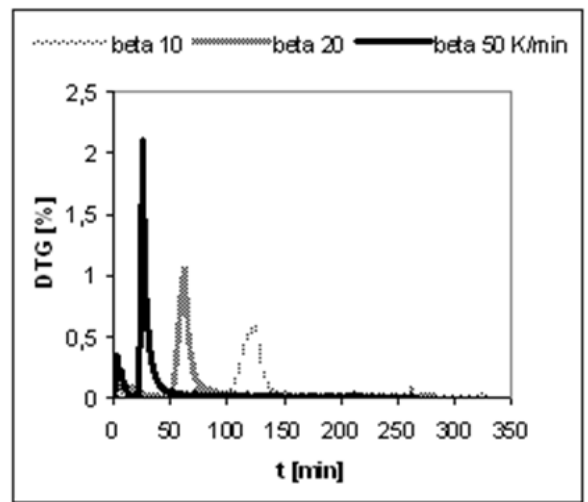

b)

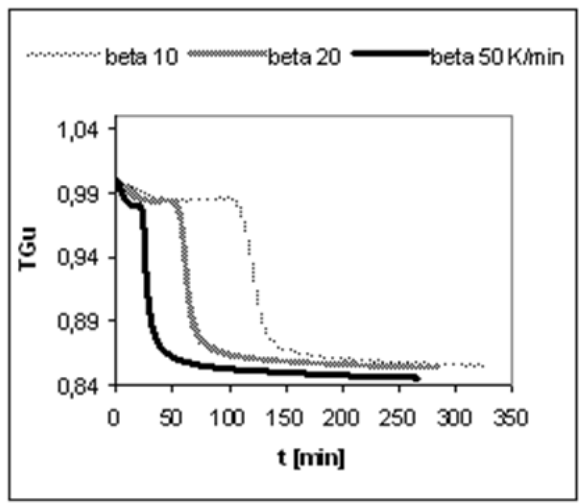

d)

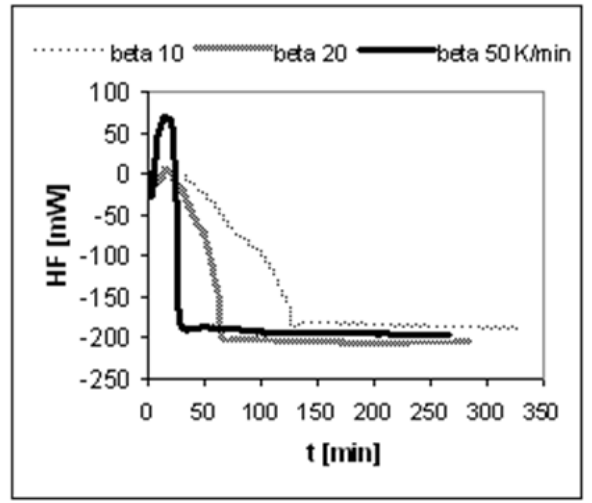

Figure 11. Plots of $T$, normalized TG function and DTG and HF in time. Heat treatment of nc-TiC/C in argon. a) temperature, b) normalized TG, c) DTG, d) HF

During the thermogravimetric measurements the evolved gaseous products were identified by mass spectrometry method. The compounds produced in the reaction with the oxygen present in trace amounts in argon, are described in detail, because these processes could affect the quality of the obtained, carbonised nc-TiC. $\mathrm{CO}_{2}-\mathrm{m} / \mathrm{e} 44, \mathrm{CO}-\mathrm{m} / \mathrm{e} 28 \mathrm{NO}-\mathrm{m} / \mathrm{e} 30$ and $\mathrm{NH}_{3}-\mathrm{m} / \mathrm{e} 17$ have been identified. $\mathrm{NH}_{3}$ formed as a result of pyrolytic decomposition of carbon compounds was the precursor of nitric oxide. $\mathrm{CO}_{2}-\mathrm{m} / \mathrm{e} 44$ mass spectrum, is shown in Figure 13 as an example. To facilitate the analysis of the results the normalized TGu function is also plotted. 


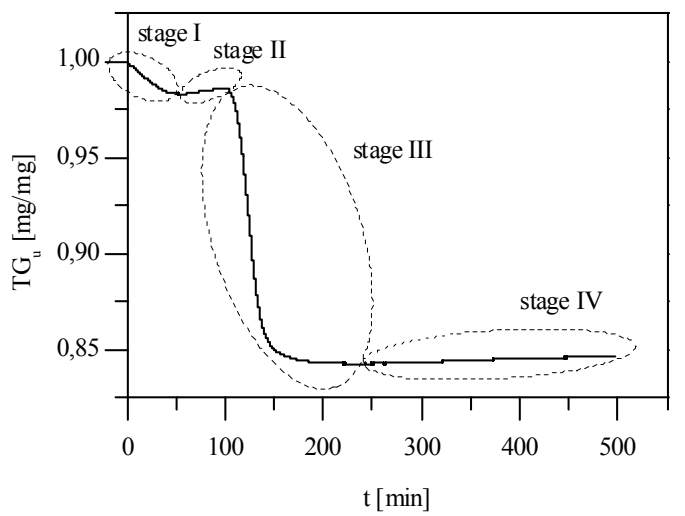

Figure 12. Plots of normalized TG functions in time for $\beta=10 \mathrm{~K} / \mathrm{min}$ and $6 \mathrm{~h}$ at $1673 \mathrm{~K}$ recorded during the heating of $\mathrm{nc}^{-} \mathrm{TiC} / \mathrm{C}$ in argon.

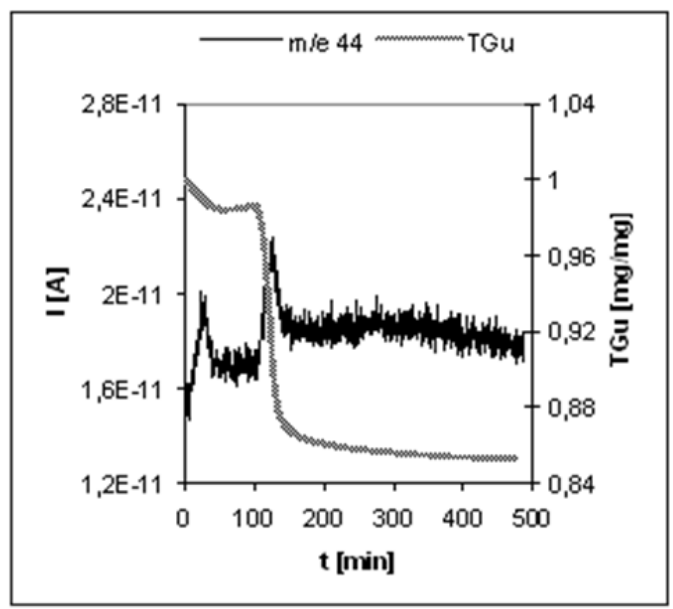

Figure 13. Mass spectra of $\mathrm{CO}_{2}$ and normalized TG function plots. Heat treatment of nc-TiC/C in argon at the heating rate $10 \mathrm{Kmin}^{-1}$.

The analysis of mass spectra allowed the more accurate characterisation of distinguished stages. In stage I volatile products were evolved. $\mathrm{CO}_{2}, \mathrm{CO}$ and $\mathrm{NO}$ were also formed. In this stage $\mathrm{H}_{2}, \mathrm{NH}_{3}, \mathrm{HCN}$ and $\mathrm{CH}_{3}-\mathrm{CH}_{3}, \mathrm{CH}_{2}=\mathrm{CH}_{2}$ and $\mathrm{CH} \equiv \mathrm{CH}$ also evolved. In stage II oxidation of non-carbonised nc-TiCx/C occurred. During the course of stage III $\mathrm{CO}$ and $\mathrm{CO}_{2}$ were emitted. They were attributed to the oxidation of released hydrocarbons. $\mathrm{HCN}, \mathrm{CH}_{3}-\mathrm{CH}_{3}$, $\mathrm{CH}_{2}=\mathrm{CH}_{2}$, and $\mathrm{CH} \equiv \mathrm{CH}$ were also formed.

The correct kinetic description was hindered by evolution of secondary products. Therefore the values of $\alpha(\mathrm{T})$ determined for each stage required an independent evaluation. 


\subsection{The results of calculations}

For distinguished stages, basing on the TG function, the conversion degree was calculated. The formula (23) was used.

During the measurements weight changes of the samples were as follows: in stage I: 10 $\mathrm{Kmin}^{-1}(1.6 \%), 20 \mathrm{Kmin}^{-1}(1.7 \%)$ and $50 \mathrm{Kmin}^{-1}(2 \%)$. In stage II, the sample weight changes equaled: $10 \mathrm{Kmin}^{-1}(0.089 \%), 20 \mathrm{Kmin}^{-1}(0.047 \%)$. Whereas in whole the range of the course of stage III weight changes were: $10 \mathrm{Kmin}^{-1}(13.47 \%), 20 \mathrm{Kmin}^{-1}(13.23 \%)$ and $50 \mathrm{Kmin}^{-1}$ $(13.66 \%)$. The obtained relations of $\alpha(\mathrm{T})$ for stages I and II are shown in Figure 14.

a)

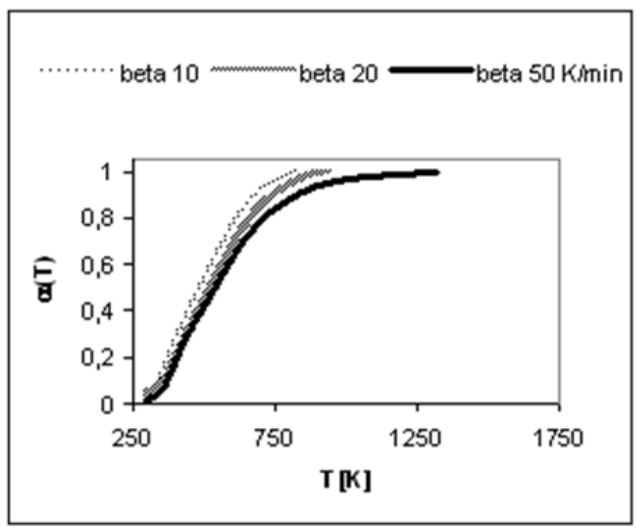

b)

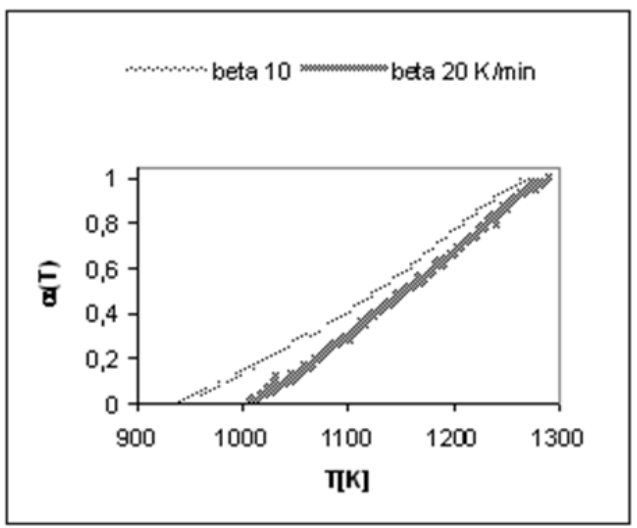

Figure 14. Temperature dependencies of $\alpha(\mathrm{T})$ function; a) stage I, b) stage II.

In accordance with the theory of kinetics of heterogeneous processes the plots of $\alpha(\mathrm{T})$ are shifted into higher temperature range along with the increase in samples heating rate.

Due to the measurements in different regimes the dependencies of $\alpha(\mathrm{T})$ determined for stage III required a more detailed discussion. The conversion degree in stage III was changing regularly in time (Fig. 15a). Irregular changes were observed in the trajectories of the curves of conversion degree dependencies on temperature (Fig. 15b). It was also found that in the transient area a significant increase in conversion degree took place.

The results presented in Figure 16a were elaborated according to the rules of non-isothermal processes theory and in Figure $16 \mathrm{~b}$ according to the isothermal processes theory.

The plots of $\alpha(\mathrm{T})$ determined for non-isothermal conditions concern the pyrolysis process.

At low temperatures, there is no carbonisation of nc-TiC, and at temperature above $1573 \mathrm{~K}$ pyrolysis proceeded much faster than carbonisation. Under the non-isothermal conditions, the transition from one temperature range to the other was short. As a result the influence of carbonisation on the recorded samples weight loss was not revealed. 
a)

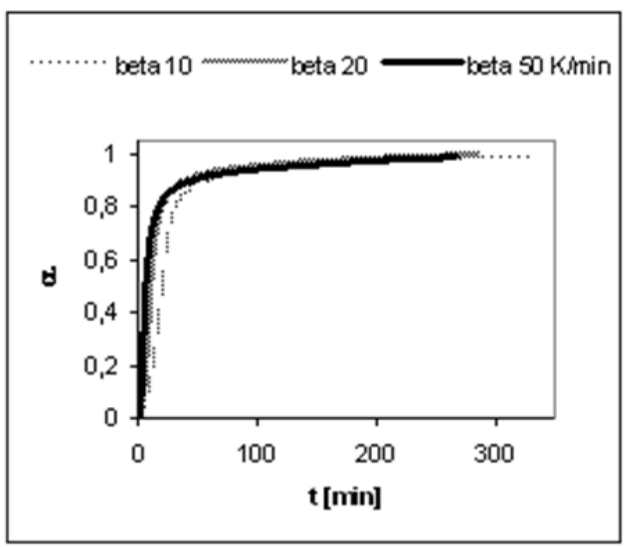

b)

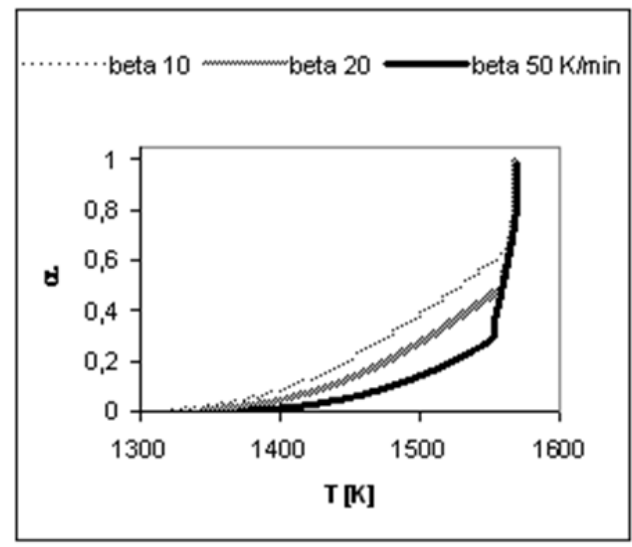

Figure 15. Total conversion degree. Stage III; a) time dependency b) temperature dependency.

a)

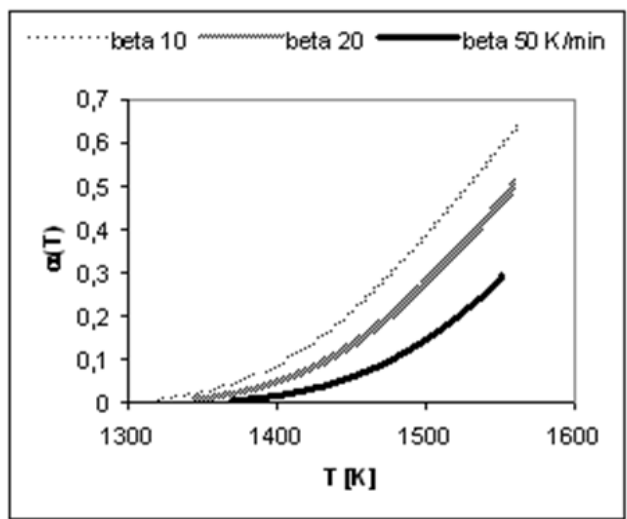

b)

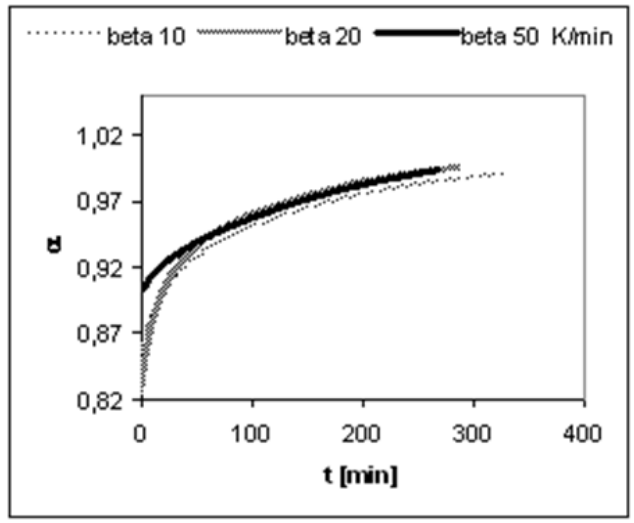

Figure 16. Conversion degree dependencies on temperature and time. Purification and carbonization of nc-TiC/C in argon. Stage II. a) non-isothermal conditions b) isothermal conditions.

The dependencies of $\alpha(\mathrm{T})$ determined for stages I, II and III under non-isothermal conditions, at a linear heating rate of the samples, were evaluated by neural networks method. The $\alpha(\mathrm{T})$ was the described variable and the sample heating rate and temperature were the describing variables. For each stage all the measurements series were analyzed simultaneously. The results are listed in Table 7

According to the theory of non-isothermal processes kinetics, the $\alpha(\mathrm{T})$ dependencies, determined for the stages, describe with high accuracy two parameters: sample heating rate 
and sample temperature. These results could therefore be used in further calculations, i.e., during the identification of kinetic models (determination of the form of $\mathrm{g}(\alpha)$ function) ) and during determination of Arrhenius parameters A and E.

\begin{tabular}{|l|c|c|c|c|c|c|c|c|c|}
\hline \multirow{2}{*}{ Parameter } & \multicolumn{3}{|c|}{ Stage I, MLP 2/2 } & \multicolumn{3}{c|}{ Stage II } & \multicolumn{3}{c|}{ Stage III, MLP 2/15 } \\
\cline { 2 - 10 } & $\mathrm{Tr}$ & $\mathrm{We}$ & $\mathrm{Te}$ & $\mathrm{Tr}$ & $\mathrm{We}$ & $\mathrm{Te}$ & $\mathrm{Tr}$ & $\mathrm{We}$ & $\mathrm{Te}$ \\
\hline S.D. Ratio & 0.0361 & 0.0355 & 0.0364 & 0.0269 & 0.0274 & 0.0284 & 0.0728 & 0.0820 & 0.0784 \\
\hline Correlation & 0.999 & 0.999 & 0.999 & 0.999 & 0.999 & 0.999 & 0.997 & 0.997 & 0.997 \\
\hline
\end{tabular}

Table 7. Estimation of $\alpha(\mathrm{T})$ dependencies determined for stage I, II and III with use of artificial neural networks method.

First, the values of these parameters were estimated by linear regression method. Each series were analysed separately. The obtained results for stage III are given, as an example, in Table 8.

\begin{tabular}{|c|c|c|c|c|c|c|c|}
\hline $\begin{array}{c}\beta \\
{[\mathrm{K} / \mathrm{min}]}\end{array}$ & $\mathrm{r}^{*}$ & $\mathrm{~F}$ & $\begin{array}{c}\mathrm{E} \\
{[\mathrm{kJ} / \mathrm{mol}]}\end{array}$ & $\begin{array}{c}\mathrm{A} \\
{[1 / \mathrm{min}]}\end{array}$ & $\begin{array}{c}\mathrm{T}_{\mathrm{m}} \\
{[\mathrm{K}]}\end{array}$ & $\Delta \alpha$ & $\Delta \mathrm{T}$ \\
\hline 10 & $-0,988$ & 50029,7 & 315,09 & $8,48 \mathrm{E} 09$ & 1530 & $0.005-0.639$ & $1321-1564$ \\
\hline 20 & $-0,988$ & 47245,7 & 327,77 & $3 \mathrm{E} 10$ & 1559 & $0.005-0.508$ & $1345-1560$ \\
\hline 50 & $-0,989$ & 20219,0 & 375,62 & $1,95 \mathrm{E} 12$ & 1590 & $0.004-0.29$ & $1370-1551$ \\
\hline
\end{tabular}

Table 8. List of kinetic parameters. Stage III, model F1.

$\mathrm{r}^{*}$ - correlation coefficient, F - Snedecor statistic

Using the determined values of $\mathrm{A}$ and E parameters, the values of $\alpha(\mathrm{T})$ were calculated from the Coats-Redfern equation. They were compared with the data determined from the measurements. The systematic error in the order of $4.5 \%$ has been noted. The accuracy was improved by correcting the value of $E$ parameter. There was required that the error in the series, i.e. the mean square error between the values determined from the measurements and calculated $\ln \left[\frac{g(\alpha)}{T^{2}}\right]$, was close to zero. The calculations for the remaining stages were performed in the same way. The results are given in Table 9.

The results have been verified. Using the kinetic parameters given in Table 9 the conversion degrees were calculated from the Coats-Redfern equation for the e stages and compared to the ones determined from measurements. As an example, in Figure 17 the results for stage I are shown. A good consistency was obtained.

The kinetic parameters determined for the stages have been used for simulation calculations. The $\alpha(\mathrm{T})$ and $\mathrm{r}(\alpha, \mathrm{T})$ dependencies on temperature and sample heating rate were investigated. The results are presented in Figure 18.

The determined dependencies are in accordance with the theory. With the increase in sample heating rates the $\alpha(\mathrm{T})$ curves are shifted into the higher temperature range. The 
process rate increases from zero for $\alpha(\mathrm{T})$ equal zero, reaches the maximum in temperature $\mathrm{Tm}$, and then usually decreases to zero at $\alpha(\mathrm{T}) \rightarrow 1$. The temperature ranges for stages runs are consistent with the ones determined experimentally. The $\alpha(\mathrm{T})$, and $\mathrm{r}(\alpha, \mathrm{T})$ plots for a stage do not come to an end, because at high conversion degrees process ran according to the different kinetic models.

\begin{tabular}{|c|c|c|c|c|c|c|c|c|}
\hline stage & Model & $\mathrm{g}(\alpha)$ & $\begin{array}{c}\beta \\
{[\mathrm{K} / \mathrm{min}]}\end{array}$ & $\begin{array}{c}\mathrm{A} \\
{[1 / \mathrm{min}]}\end{array}$ & $\begin{array}{c}\mathrm{E} \\
{[\mathrm{kJ} / \mathrm{mol}]}\end{array}$ & $\begin{array}{c}\mathrm{T}_{\mathrm{m}} \\
{[\mathrm{K}]}\end{array}$ & $\Delta \alpha$ & $\begin{array}{l}\Delta \mathrm{T} \\
{[\mathrm{K}]} \\
\end{array}$ \\
\hline \multirow{3}{*}{ I } & \multirow{3}{*}{ D3 } & \multirow{3}{*}{$\frac{3}{2}\left[1-(1-\alpha)^{\frac{1}{3}}\right]^{2}$} & 10 & 2,2 E-6 & 15,8 & 487,4 & $\begin{array}{c}0,03- \\
0.9989\end{array}$ & $299-826$ \\
\hline & & & 20 & 1,2E-6 & 16,5 & 524,9 & $\begin{array}{l}0,035- \\
0,9969\end{array}$ & 299-937 \\
\hline & & & 50 & $3,5 \mathrm{E}-7$ & 16,3 & 539,5 & $\begin{array}{l}0.005- \\
0.9995 \\
\end{array}$ & $\begin{array}{l}298- \\
1319 \\
\end{array}$ \\
\hline \multirow{2}{*}{ II } & \multirow{2}{*}{ F2 } & \multirow{2}{*}{$(1-\alpha)^{-1}-1$} & 10 & $6,81 \mathrm{E} 4$ & 125,25 & 1128 & $\begin{array}{c}0.002- \\
0.999 \\
\end{array}$ & $\begin{array}{l}935- \\
1271 \\
\end{array}$ \\
\hline & & & 20 & 7,74 E6 & 160,8 & 1156 & $\begin{array}{c}0.002- \\
0.999\end{array}$ & $\begin{array}{l}1007- \\
1291\end{array}$ \\
\hline \multirow{3}{*}{ III } & \multirow{3}{*}{$\mathrm{F} 1$} & \multirow{3}{*}[-\operatorname{ln}(1-\alpha)]{} & 10 & $\begin{array}{l}8,48 \\
\text { E09 }\end{array}$ & 306,8 & 1530 & $\begin{array}{c}0.005- \\
0.639 \\
\end{array}$ & $\begin{array}{c}1321- \\
1564 \\
\end{array}$ \\
\hline & & & 20 & 3 E10 & 318,8 & 1559 & $\begin{array}{c}0.005- \\
0.508 \\
\end{array}$ & $\begin{array}{c}1345- \\
1560 \\
\end{array}$ \\
\hline & & & 50 & $\begin{array}{l}1,95 \\
\text { E12 }\end{array}$ & 364,5 & 1590 & $0.004-0.29$ & $\begin{array}{c}1370- \\
1551\end{array}$ \\
\hline
\end{tabular}

Table 9. List of kinetic parameters for the stages.

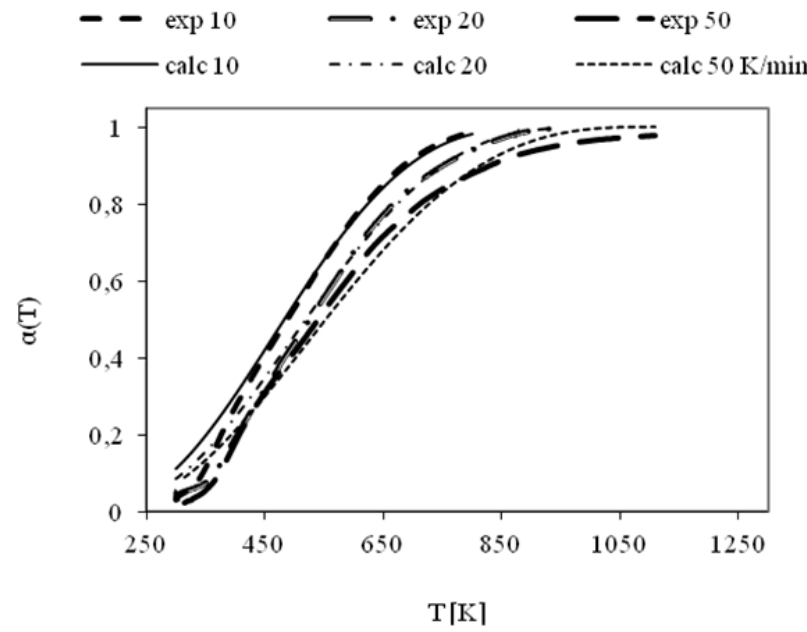

Figure 17. Comparison of $\alpha(\mathrm{T})$ calculated and determined from experiments. Stage I, model D3. 
a)

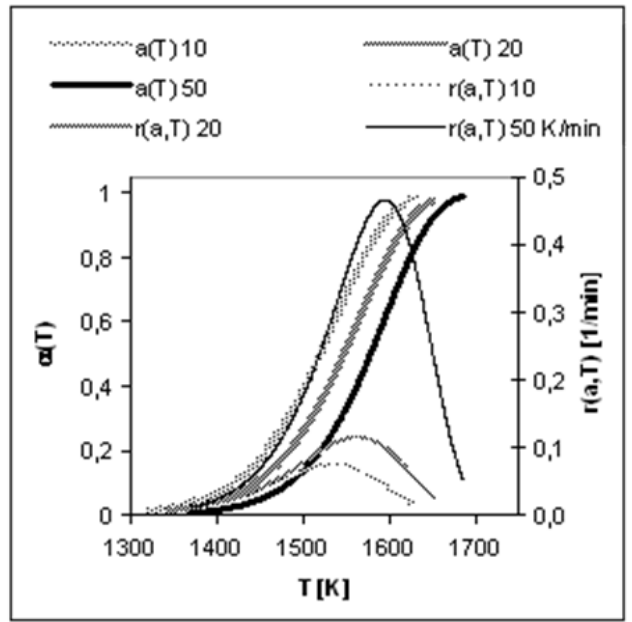

b)

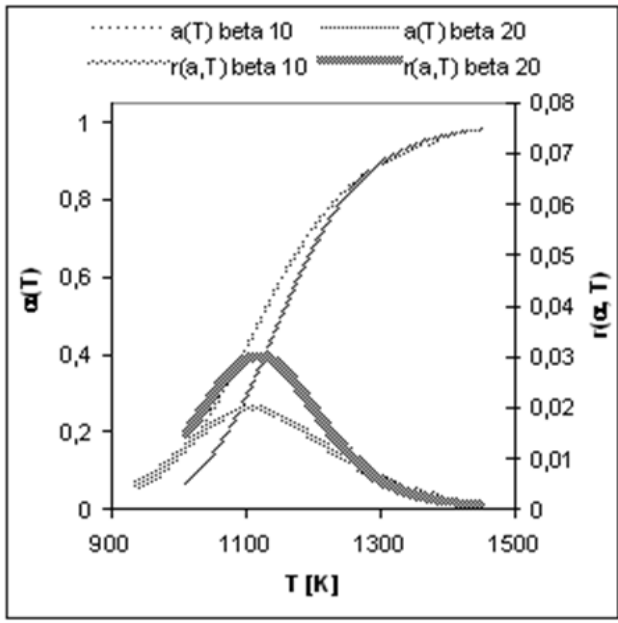

c)

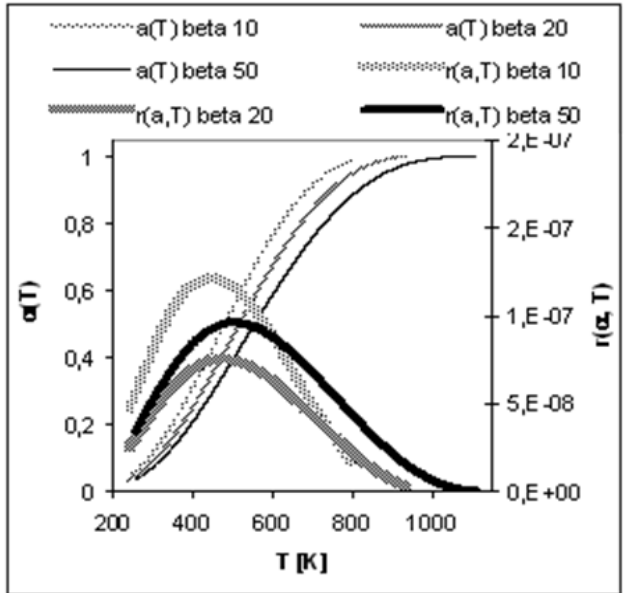

Figure 18. Plots of $\alpha(\mathrm{T})$ and $\mathrm{r}(\alpha, \mathrm{T})$ functions; a) stage I, model D3; b) stage II, model F2; c) stage III, model F1.

Under the isothermal conditions the last phase of stage III and whole the stage IV proceeded. The results presented earlier, obtained in the series up to 1573,1673 and $1773 \mathrm{~K}$, were not sufficient for description of the course of stage III under isothermal conditions. They have been complemented by additional measurements. During the investigations samples were heated up to $1343,1503,1543$ and $1623 \mathrm{~K}$ using the following heating rates: 10 , $20 \mathrm{Kmin}^{-1}$.

While elaborating these results the calculations for stages I, II and III were also performed. There were obtained similar results as before (Table 9). These data are not provided. At the 
high conversion degrees in stage III the change of kinetic model (form of $\mathrm{g}(\alpha)$ function) took place. Under the isothermal conditions, at lower conversion degrees, the process first proceeded according to the F1 model (similarly as under the non-isothermal conditions), then at high conversion degrees (higher than 0.98 ) according to the D3 (three-dimensional diffusion Jander's model). This concerns the removal of remaining products of pyrolysis.

The charts of $\alpha$ (T) were obtained from about 25,000 measurement points for each case. The value of $k(T)$ was calculated by linear regression method for the subsequent sets, each containing 1100 values of the $\mathrm{g}(\alpha)$ function. The results were evaluated using several measures. The values of $\mathrm{R}^{2}$ measure were determined. The calculation results for all measurement series are given in Table 5. The temperature, the mean values of $\mathrm{k}(\mathrm{T})$ determined for the entire sets, the time of obtaining the isothermal conditions $t_{1}$, counted from the beginning of the measurement, and the conversion degree $\alpha_{1}$ obtained for this time are given.

\begin{tabular}{|c|c|c|c|c|c|c|}
\hline series & $\beta[\mathrm{K} / \mathrm{min}]$ & $\mathrm{T}[\mathrm{K}]$ & $\mathrm{k}^{*} 10^{3}[1 / \mathrm{min}]$ & $\mathrm{t}_{1}$ & $\alpha_{1}$ & $\mathrm{R}^{2}$ \\
\hline $1443 \mathrm{~K}$ & 10 & 1440,9 & 13,61 & 158,4 & 0,7092 & 99,72 \\
\hline & 20 & 1440,9 & 14,41 & 99,98 & 0,69 & 99,92 \\
\hline $1503 \mathrm{~K}$ & 10 & 1501,1 & 14,75 & 203,92 & 0,9553 & 99,68 \\
\hline & 20 & 1501 & 35,18 & 92,85 & 0,872 & 99,59 \\
\hline $1543 \mathrm{~K}$ & 10 & 1541,4 & 9,39 & 201,72 & 0,9331 & 99,72 \\
\hline & 20 & 1541,3 & 12,48 & 142,69 & 0,9539 & 99,87 \\
\hline $1573 \mathrm{~K}$ & 10 & 1568,5 & 6,94 & 199,19 & 0,9303 & 99,36 \\
\hline & 20 & 1568,2 & 8,3 & 131,15 & 0,938 & 99,85 \\
\hline $1623 \mathrm{~K}$ & 10 & 1620,2 & 40,63 & 162,6 & 0,9653 & 99,91 \\
\hline & 20 & 1619,7 & 61,84 & 91,8 & 0,9615 & 99,95 \\
\hline $1673 \mathrm{~K}$ & 10 & 1669,4 & 54,28 & 160,2 & 0,9699 & 99,69 \\
\hline & 20 & 1669,1 & 104,31 & 86 & 0,9883 & 99,39 \\
\hline $1773 \mathrm{~K}$ & 10 & 1770,5 & 219,28 & 154,2 & 0,9831 & 99,72 \\
\hline & 20 & 1770 & 242,24 & 83,6 & 0,9831 & 99,52 \\
\hline
\end{tabular}

Table 10. The results of kinetic calculations for isothermal conditions. F1 model.

$\mathrm{R}^{2}$ - statistical measure

In the considered range of temperature two processes preceded simultaneously; pyrolysis of organic compounds, contained in the raw samples and proceeding with their participation carbonisation of $\mathrm{nc}^{-\mathrm{TiC}} \mathrm{C} / \mathrm{C}$. The bounded carbon remains in the system. As a result the lesser sample mass losses were observed. In lower temperature proceeds also pyrolysis, as shown by the values of $\mathrm{k}(\mathrm{T})$ given in Table 10. Carbonisation starts at temperature of about $1541 \mathrm{~K}$ and becomes a dominating process at temperature of about $1570 \mathrm{~K}$. At $1610 \mathrm{~K}$ pyrolysis becomes a dominating process again. With regard to carbonisation effectiveness, the process should be carried out at temperature of about $1570 \mathrm{~K}$. The minimum on the curve $\mathrm{k}(\mathrm{T})$ has been observed in Figure 19. 


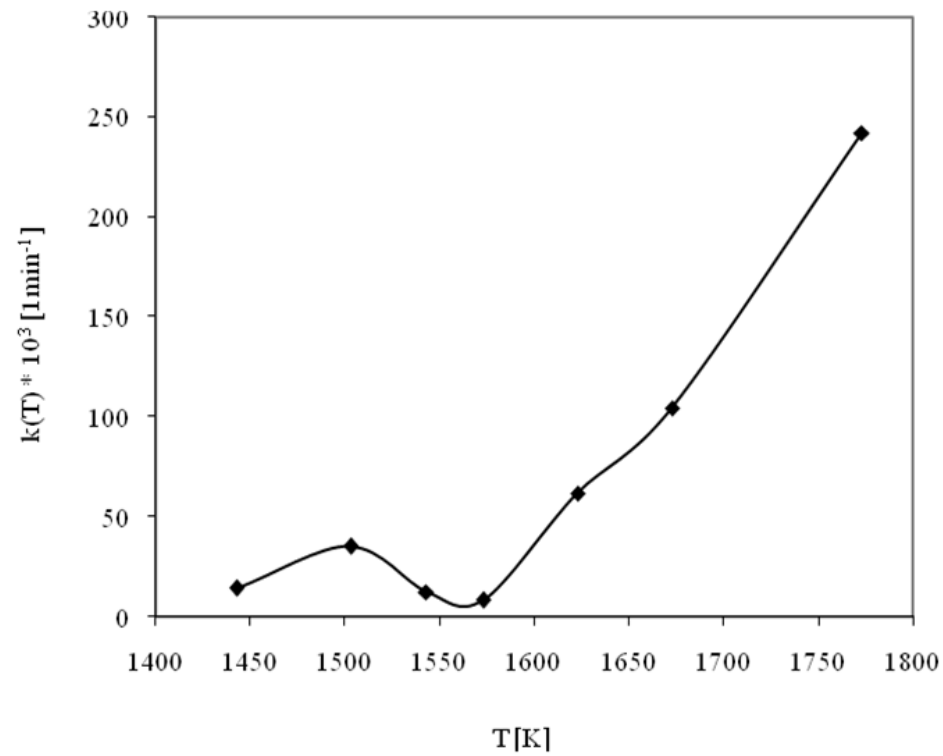

Figure 19. Dependency of reaction rate constant on temperature for $\beta=20 \mathrm{~K} / \mathrm{min}$. F1 model $(\mathrm{g}(\alpha)=[-$ $\ln (1-\alpha)]) ;-$ mean value of $\mathrm{k}(\mathrm{T})$

In the same manner were obtained the results presented in Table 11, concerning the desorption process of volatile products after the completion of carbonisation process.

\begin{tabular}{|c|c|c|c|c|c|c|}
\hline series & $\beta[\mathrm{K} / \mathrm{min}]$ & $\mathrm{T}[\mathrm{K}]$ & $\mathrm{k}^{*} 10^{3}[1 / \mathrm{min}]$ & $\mathrm{t}_{2}$ & $\alpha_{2}$ & $\mathrm{R}^{2}$ \\
\hline $1543 \mathrm{~K}$ & 10 & 1541,4 & 0,255 & 402,3 & 0,989 & 97,82 \\
\hline & 20 & 1541,3 & 0,354 & 326,2 & 0,9933 & 95,03 \\
\hline $1573 \mathrm{~K}$ & 10 & 1568,5 & 1,47 & 221,76 & 0,9412 & 99,59 \\
\hline & 20 & 1568,2 & 2,34 & 150,98 & 0,9486 & 99,65 \\
\hline $1673 \mathrm{~K}$ & 10 & 1669,4 & 9,5 & 160,2 & 0,9699 & 99,69 \\
\hline & 20 & 1669,1 & 16,07 & 87 & 0,9892 & 99,45 \\
\hline $1773 \mathrm{~K}$ & 10 & 1770,5 & 41,08 & 154,18 & 0,9831 & 99,66 \\
\hline & 20 & 1770 & 49,36 & 84,1 & 0,9854 & 99,57 \\
\hline
\end{tabular}

Table 11. The results of kinetic calculations for isothermal conditions. D3 model

In the third column the values of $k(T)$ are given, and in the subsequent columns time $t_{2}$ from which desorption becomes the dominant factor, and the corresponding conversion degree.

Under the measurement conditions the oxidation of carbonised nc-TiC, by the oxygen contained in trace amounts in argon, occurred in series up to 1673 and $1773 \mathrm{~K}$. This process proceeded according to the R2 model (reaction at the interface, cylindrical symmetry) or R3 model (reaction at the interface, spherical symmetry). The weight gain of the sample was less than $1 \%$. Inhibition of oxidation process of carbonised nc-TiC can be explained on the 
basis of the mechanism of Shimada [26], the formation on the surface of nc-TiC particles of amorphous $\mathrm{TiO}_{2}$ layer, blocking access of oxygen to the reaction zone. The given values of $\mathrm{k}(\mathrm{T})$ indicate that the samples obtained at heating rates of $10 \mathrm{~K} / \mathrm{min}$ oxidized slower than at the heating rates of 20 and $50 \mathrm{~K} / \mathrm{min}$. It is also visible that the final temperature of the process affects the properties of carbonised nc-TiC. Basing on the series up to 1673 and 1773 $\mathrm{K}$ there was found that after the completion of carbonisation and purification process of nc$\mathrm{TiC}$, at higher temperatures oxidation of the carbonised nc-TiC by oxygen present in argon in trace amounts takes place.

The removal of carbon from the matrix and carbonisation of $\mathrm{nc}-\mathrm{TiC} \mathrm{C}_{\mathrm{x}}$ proceeded most preferably in a series up to $1573 \mathrm{~K}$, at the heating rate of $20 \mathrm{~K} / \mathrm{min}$. The results of investigations concerning this series are therefore given.

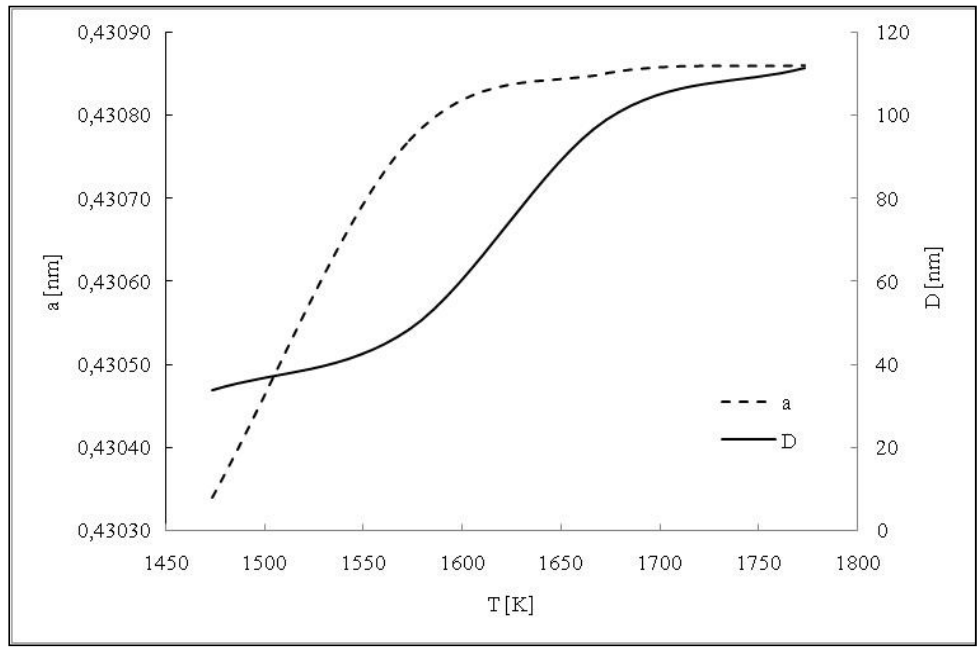

Figure 20. Dependency of nc-TiC mean lattice parameters (a) and mean particles diameters (D) on temperature [32].

Carbonisation resulted in an increase of lattice parameter of titanium carbide. The largest increase in lattice parameter was observed for the series up to $1573 \mathrm{~K}$. Under these conditions, the average particle size was in the order of $40 \mathrm{~nm}$. Mean values of lattice parameters of nc-TiC and the average particle size determined after the carbonisation processes are shown in Figure 20. The measurement of crystallites size by Scherrer method and on the basis of TEM images showed that the mean size of TiC crystallites after carbonisation was approximately $30 \%$ higher in relation to the size before the heat treatment process at temperature of $1573 \mathrm{~K}$. The results of microscopic examination were confirmed by the results of the X-ray diffraction. The analysis of chemical composition and phase composition showed an increase in the fraction of carbon in titanium carbide from $\mathrm{TiC} .68$ to TiC $.8 \div .85$ and removal of carbon from the matrix. The results of this step of research are given in $[6,32]$. 


\section{Oxidation of the $\mathrm{nc}^{-\mathrm{TiC}} \mathrm{x} / \mathrm{C}$ and $\mathrm{nc}^{-T i C} \mathrm{x}$}

The possibility of implementing purification of $\mathrm{TiC}_{\mathrm{x}} / \mathrm{C}$ composites by burning out the elementary carbon, composing matrix, was considered. The results of oxidation of $n c-\mathrm{TiC}_{\mathrm{x}} / \mathrm{C}$ system have been presented. Oxidation of the $\mathrm{TiC}_{\mathrm{x}} / \mathrm{C}$ powders, being an intermediate product of sol-gel synthesis, and of the $\mathrm{TiC}_{\mathrm{x}}$ powders obtained by reduction with hydrogen was investigated. The reduction of $\mathrm{TiC}_{\mathrm{x}} / \mathrm{C}$ powders with hydrogen aimed at removing from the system the carbon from the matrix. Purification with hydrogen according to the reaction $\mathrm{C}+\mathrm{H}_{2} \rightarrow \mathrm{CH}_{4}$ was carried out at temperature of $1173 \mathrm{~K}$, under pressure of $16 \mathrm{MPa}$, for $4.5 \mathrm{~h}$ [6,32]. The measurements were carried out using thermogravimetric method, under nonisothermal conditions. The samples unreduced with hydrogen were studied at the following heating rates: $5 \mathrm{Kmin}^{-1}$ (sample weight of $18.749 \mathrm{mg}$ ), $10 \mathrm{Kmin}^{-1}$ (sample weight of 16.049 $\mathrm{mg}$ ), $15 \mathrm{Kmin}^{-1}$ (sample weight of $13.322 \mathrm{mg}$ ), $20 \mathrm{Kmin}^{-1}$ (sample weight of $15.908 \mathrm{mg}$ ). The powders after reduction with hydrogen instead were studied at $5 \mathrm{Kmin}^{-1}$ (sample weight of $17.768 \mathrm{mg}$ ), $10 \mathrm{Kmin}^{-1}$ (sample weight of $17.174 \mathrm{mg}$ ), $15 \mathrm{Kmin}^{-1}$ (sample weight of 17.544 $\mathrm{mg}$ ), $20 \mathrm{Kmin}^{-1}$ (sample weight $17.544 \mathrm{mg}$ ). During the measurements temperature of samples, TG, DTG, and HF were recorded. In one series several dozen thousands of each variable values were recorded. During the measurements the linear change of sample temperature over time was maintained, as required by the theory of non-isothermal kinetics. The normalized TG curves of the samples unreduced and reduced with hydrogen are shown in Figure 21.

a)

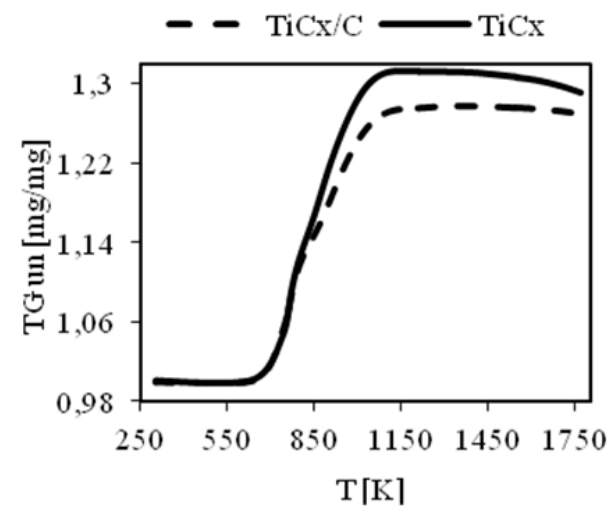

b)

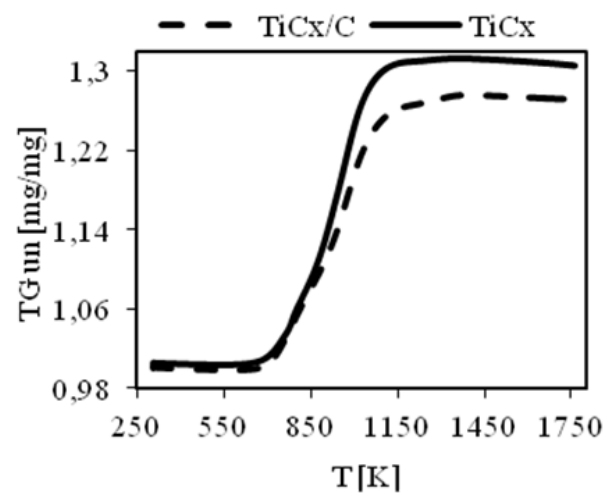

Figure 21. Plots of $\mathrm{TG}$ curves for $\mathrm{TiC}_{\mathrm{x}} / \mathrm{C}$ samples and $\mathrm{TiC} \mathrm{C}_{\mathrm{x}}$ (after reduction with $\mathrm{H}_{2}$ ) samples, a) 5, b) 20 $\mathrm{Kmin}^{-1}$

The normalized TGu curves of the samples reduced with hydrogen are shifted upward to the same degree for different heating rates $(\Delta \mathrm{TG}$ in the order of $0.03 \mathrm{mg})$, because in the $\mathrm{TiC} x$ powders (after reduction with hydrogen), the relative content of titanium increased as a result of removing elemental carbon by acting with hydrogen. This resulted in greater weight gain of $\mathrm{TiC}_{x}$ during the oxidation in comparison with $\mathrm{TiC}_{x} / \mathrm{C}$. In both cases the 
weight gain of the sample started at temperature in the order of $600 \mathrm{~K}$. This means that under these conditions the oxidation of $\mathrm{nc}^{-T i C} \mathrm{x}$ started.

In the DTG curves, there are three peaks (Fig. 22). The first peak is associated with start of the oxidation of $\mathrm{nc}^{-T i C}$. The subsequent weight loss is associated with the burning out of the elemental carbon, produced during the oxidation of the $\mathrm{nc}^{-\mathrm{TiC}} \mathrm{x}$. This process proceeds simultaneously with the further oxidation of nc-TiCx. The next peak concerns the oxidation of unreacted $n c-T_{i C}$. The elemental carbon, contained in $\mathrm{nc}^{-\mathrm{TiC}} \mathrm{C} / \mathrm{C}$ samples unreduced with hydrogen, burns out in the final stage of the process.

a)

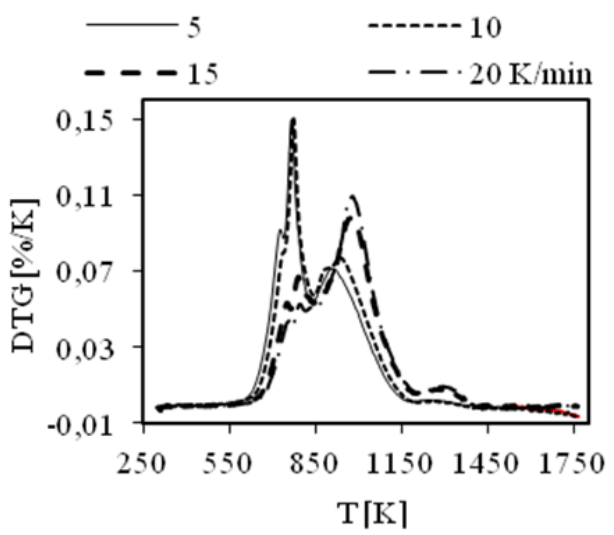

b)

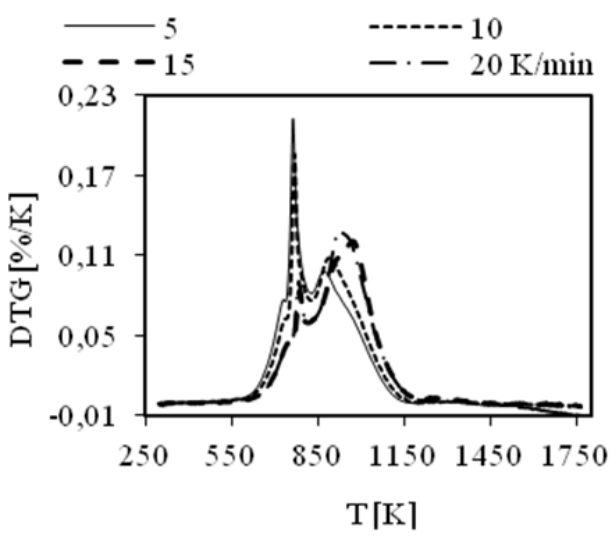

Figure 22. Dependency of DTG curves on temperature, a) for $\mathrm{TiC}_{x} / \mathrm{C}, \mathrm{b}$ ) for $\mathrm{TiC}_{\mathrm{x}}$ (after reduction with $\mathrm{H}_{2}$ )

Two distinct maxima were observed in the HF plots (Fig. 23). The first one is associated with the beginning of oxidation process of $\mathrm{nc}^{-\mathrm{TiC}} \mathrm{x}$ and the second one with burning out of the elemental carbon, produced during the oxidation of the $\mathrm{nc}^{-\mathrm{TiC}} \mathrm{x}$, and further course of the $\mathrm{nc}^{-\mathrm{TiC}} \mathrm{x}$ oxidation. The apparent increase in the value of HF function, in the final stage of the process, is associated with the terminating oxidation of nc-TiCx.

The results have been confirmed by the identification of $\mathrm{CO}_{2}$, formed in the system, by mass spectrometry. There was also found that while increasing sample heating rates the plots of mass spectra of $\mathrm{CO}_{2}$, originating from the nc-TiC oxidation process and from burning out of the formed carbon, overlapped. The carried out experiments have shown that the nc-TiC, obtained by sol-gel process, cannot be purified by burning out in the air the carbon admixtures contained in the system.

The performed studies indicated also the possibility of occurring during the description of oxidation of ceramic nc-TiC/C powders in the air, some difficult issue related to the simultaneous proceeding, in a certain range of temperature, of metal carbide oxidation and burning out of the carbon. The following manner of kinetics description of the both concurrent reactions, based on thermogravimetric studies, has been proposed. 
a)

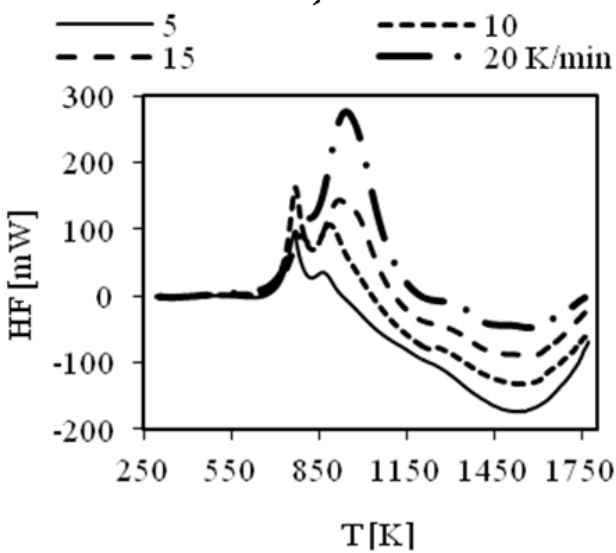

b)

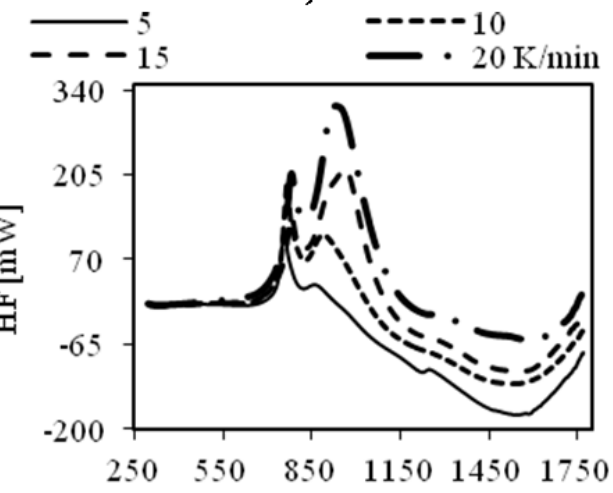

$\mathrm{T}\lceil\mathrm{K}\rceil$

Figure 23. Dependency of $\mathrm{HF}$ on temperature, a) for $\mathrm{TiC}_{x} / \mathrm{C}, \mathrm{b}$ ) for $\mathrm{TiC}_{\mathrm{x}}$ (after reduction with $\mathrm{H}_{2}$ )

To obtain the normalized TGu curve, corresponding to the oxidation process of $\mathrm{TiC}_{\mathrm{x}}$ in the whole range of temperature the neural networks method was applied. Basing on the results registered before burning out of the formed carbon and after the end of this process the network was fitted. Then the fitted network was used to generate the segment of normalized TGu curve for the temperature range in which both transformations proceeded simultaneously. The multi-layer MLP networks were used. The described variable was TGu function, and the describing variable was temperature. Each measurement series was analysed separately. Using these models sections of TG curves corresponding to the oxidation process of $\mathrm{nc}-\mathrm{TiC}$, in the temperature range in which this process proceeded simultaneously with the burning out of the carbon, were generated. The TGu plots generated by the network and determined experimentally are shown in Figure 24.

a)

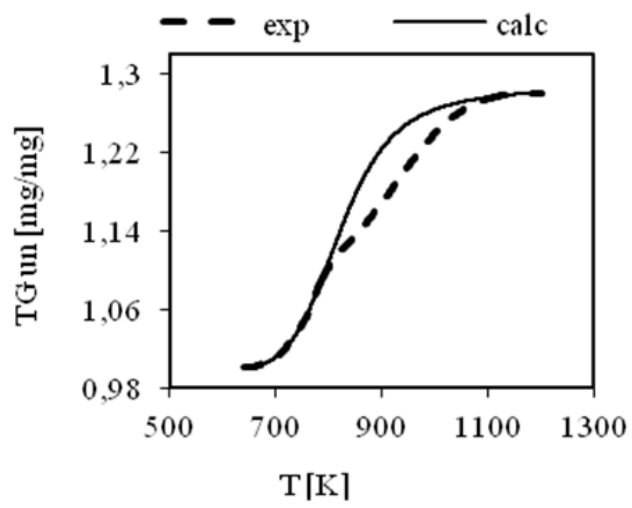

b)

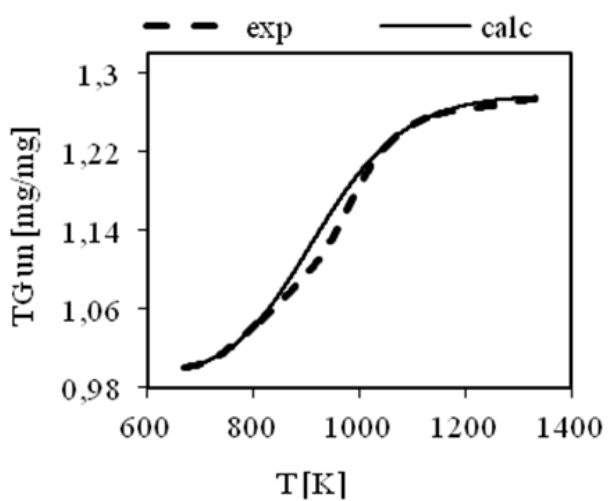

Figure 24. Plots of $\mathrm{TGu}$ function, calculated and experimental. Oxidation of $\mathrm{nc}-\mathrm{TiC} \times \mathrm{C}$ samples, unreduced by hydrogen, in air, a) $5 \mathrm{Kmin}^{-1}$, b) $20 \mathrm{Kmin}^{-1}$ 
On the basis of TGu curves, complemented by the results of calculations, the $\alpha(\mathrm{T})$ dependencies for the oxidation process of $\mathrm{nc}-\mathrm{TiCx}$ in the whole temperature range were determined.

The conversion degree for the process of burning out the elemental carbon was determined as follows. By subtracting the experimental values from the calculated TGu values, $\triangle \mathrm{TG}$ was determined, and then, integrating numerically, TGu curves for the process of burning out the carbon were determined. The $\alpha(\mathrm{T})$ dependencies obtained for both processes, are presented in the form of graphs in Figure 25.

a)

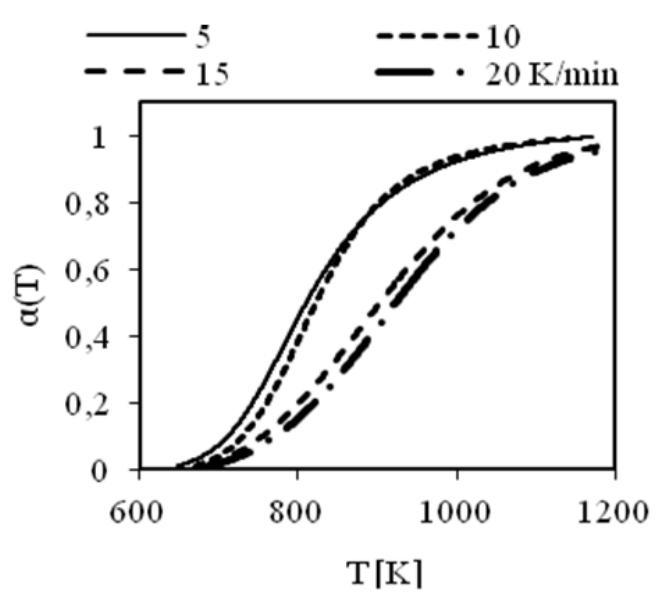

b)

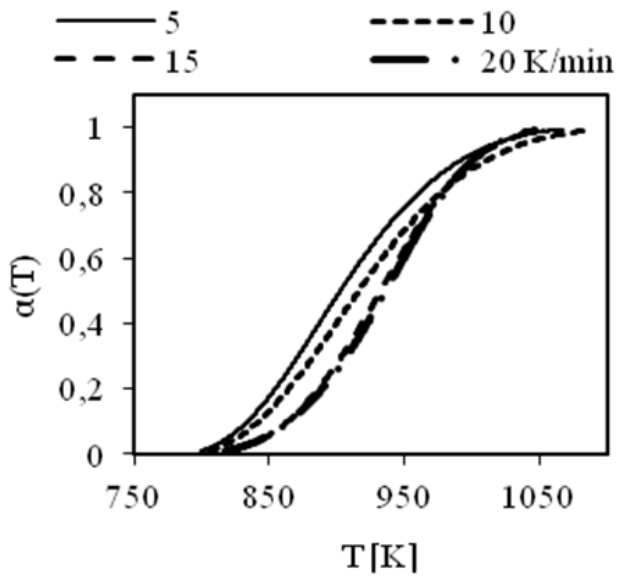

Figure 25. The $\alpha(\mathrm{T})$ dependencies. Oxidation of unreduced nc-TiC $/ \mathrm{C}$ in air, a) oxidation of nc-TiCx, b) burning out of elemental carbon

According to the theory, along with the increase in sample heating rates, the plots of $\alpha(\mathrm{T})$ are shifted into the higher temperature range.

The conversion degree for the process of burning out the carbon in the matrix (the second temperature range) was calculated in the same way. In the case of the oxidation process of $\mathrm{nc}^{-\mathrm{TiC}} \mathrm{x}$ (after reduction with hydrogen) two stages occurred: $\mathrm{nc}^{-\mathrm{TiC}} \mathrm{x}$ oxidation and burning out of the elemental carbon formed at the beginning of the oxidation process of nc-TiC. The $\alpha(\mathrm{T})$ dependence was determined for all the stages in the same way. The determined $\alpha(\mathrm{T})$ dependencies were the basis of kinetic studies. The Coats-Redfern equation was used. For all the stages kinetic models and Arrhenius parameters were determined (Table 12).

These data contain the full information about the kinetics of analysed processes. There should be noted that the kinetic parameters (the forms of $\mathrm{g}(\alpha)$ functions and the values of $\mathrm{A}$ and E) determined on the basis of experimental data, should correspond to their physicochemical meaning. In the analysed case, the F2 model $\left[g(\alpha)=(1-\alpha)^{-1}-1\right]$, having a theoretical justification, was used, and the determined activation energy values are similar to those found in many chemical reactions. 


\begin{tabular}{|c|c|c|c|c|c|c|c|c|}
\hline Sample & Conversion & Model & $\begin{array}{c}\mathrm{B} \\
{[\mathrm{K} / \mathrm{min}]}\end{array}$ & $\mathrm{A}[1 / \mathrm{min}]$ & \begin{tabular}{|c|}
$\mathrm{E}$ \\
{$[\mathrm{kJ} / \mathrm{mol}]$} \\
\end{tabular} & $\mathrm{T}_{\mathrm{m}}[\mathrm{K}]$ & $\Delta \alpha$ & $\Delta \mathrm{T}[\mathrm{K}]$ \\
\hline \multirow{10}{*}{$\mathrm{TiC}_{x} / \mathrm{C}$} & \multirow{4}{*}{$\mathrm{TiC}$} & \multirow{4}{*}{$\mathrm{F} 2$} & 5 & 26343,35 & 88,31 & 810,45 & $0,01-0,99$ & 648-1147 \\
\hline & & & 10 & 291522,00 & 99,20 & 822,77 & $0,01-0,99$ & $671-1141$ \\
\hline & & & 15 & 16689,12 & 86,70 & 903,79 & $0,02-0,99$ & $691-1245$ \\
\hline & & & 20 & 22863,39 & 89,26 & 923,22 & $0,01-0,99$ & $690-1295$ \\
\hline & \multirow{4}{*}{ Celemental } & \multirow{4}{*}{ F2 } & 5 & $1,76 \mathrm{E}+10$ & 185,04 & 902,35 & $0,02-0,99$ & 803-1058 \\
\hline & & & 10 & $8,27 \mathrm{E}+09$ & 177,71 & 916,13 & $0,02-0,99$ & 809-1085 \\
\hline & & & 15 & $4,74 \mathrm{E}+12$ & 222,13 & 932,37 & $0,02-0,98$ & 827-1046 \\
\hline & & & 20 & $7,1 \mathrm{E}+12$ & 223,18 & 936,23 & $0,01-0,99$ & $817-1042$ \\
\hline & \multirow{2}{*}{$\mathrm{C}_{\text {matrix }}$} & \multirow{2}{*}{ F2 } & 15 & $5,24 \mathrm{E}+16$ & 391,91 & 1243,06 & $0,02-0,98$ & $1142-1366$ \\
\hline & & & 20 & $7,22 \mathrm{E}+16$ & 392,43 & 1246,63 & $0,02-0,99$ & $1138-1373$ \\
\hline \multirow{8}{*}{$\begin{array}{l}\mathrm{TiC} \times \text { after } \\
\text { reduction }\end{array}$} & \multirow{4}{*}{$\mathrm{TiC}$} & \multirow{4}{*}{ F2 } & 5 & $1,01 \mathrm{E}+06$ & 106,33 & 809,11 & $0,01-0,99$ & $645-983$ \\
\hline & & & 10 & $1,37 \mathrm{E}+05$ & 95,18 & 838,82 & 0,01-0,99 & 649-1134 \\
\hline & & & 15 & $1,70 \mathrm{E}+05$ & 98,51 & 892,95 & $0,01-0,99$ & 673-1153 \\
\hline & & & 20 & $3,19 \mathrm{E}+05$ & 100,63 & 886,78 & $0,01-0,99$ & $668-1144$ \\
\hline & \multirow{4}{*}{ Celemental } & \multirow{4}{*}{ F2 } & 5 & $6,98 \mathrm{E}+09$ & 178,41 & 902,90 & $0,02-0,99$ & $803-1063$ \\
\hline & & & 10 & $6,44 \mathrm{E}+09$ & 174,85 & 908,97 & $0,02-0,99$ & $810-1078$ \\
\hline & & & 15 & $1,55 \mathrm{E}+12$ & 214,49 & 933,09 & $0,02-0,99$ & $832-1063$ \\
\hline & & & 20 & $5,19 \mathrm{E}+11$ & 204,20 & 930,08 & $0,02-0,99$ & 830-1071 \\
\hline
\end{tabular}

Table 12. List of kinetic data for the transformations in oxidation processes of titanium carbide samples before and after the reduction with $\mathrm{H}_{2}$.

Basing on the obtained results an analysis of the process has been performed. The $r(\alpha, T)$ dependencies on sample heating rates and sample temperature for the stages were studied. The plots of $\mathrm{r}(\alpha, \mathrm{T})$ obtained for the $\mathrm{nc}^{-\mathrm{TiC}} / \mathrm{C}$ not-reduced with hydrogen are shown in Figure 26.
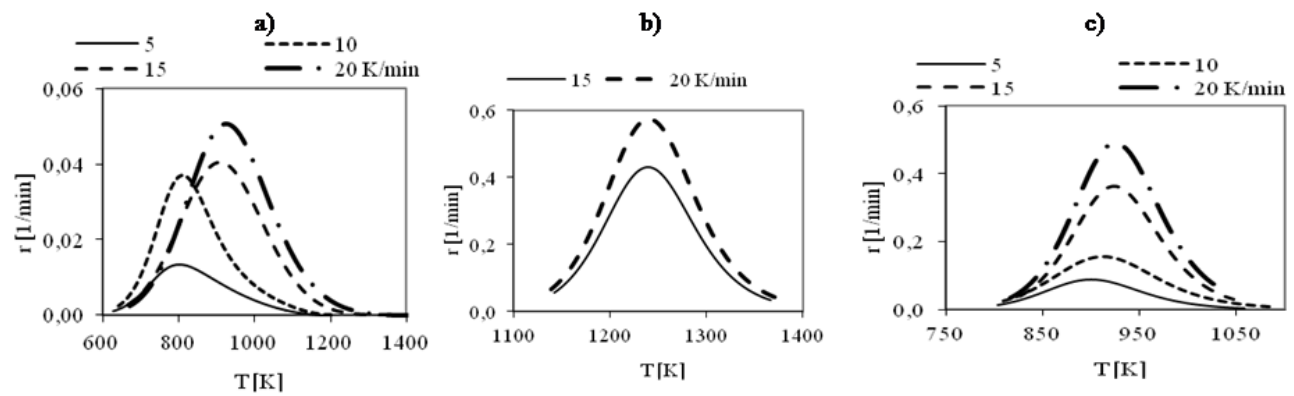

Figure 26. Plots of $\mathrm{r}(\alpha, \mathrm{T})$. Oxidation of $\mathrm{nc}_{-}-\mathrm{TiC}_{\mathrm{x}} / \mathrm{C}$ unreduced with hydrogen; a) oxidation of $\left.\mathrm{nc}_{-} \mathrm{TiC}_{\mathrm{x}}, \mathrm{b}\right)$ burning out of the carbon formed during the oxidation process of nc-TiC, c) burning out of the carbon contained in the samples 
According to the theory of kinetics of non-isothermal processes the reaction rate should increase along with the increase in sample heating rates. This condition is not well fulfilled for the oxidation process of $\mathrm{nc}^{-\mathrm{TiC}} \mathrm{x}$ unreduced with hydrogen (Fig.26a). This means that the samples used in measurement series differed. For the both processes of burning out the carbon the results consistent with theory were obtained. There should be noted that according to the theory, in each stage the process rate increases from zero for $\alpha(\mathrm{T})=0$, reaches the maximum in temperature $\mathrm{Tm}$, and then decreases to zero at $\alpha(\mathrm{T}) \rightarrow 1$. The temperature ranges determined for the stages runs on the basis of calculations are consistent with the ones determined experimentally.

The analogous plots obtained for the oxidation process in air of $\mathrm{nc}^{-\mathrm{TiC}} \mathrm{x}$ reduced with hydrogen are shown in Figure 27.

a)

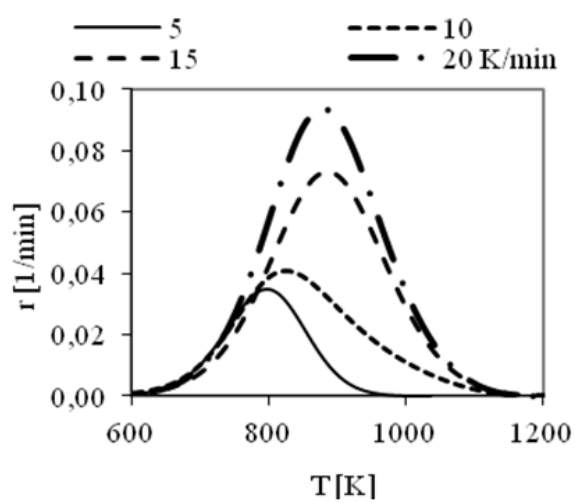

b)

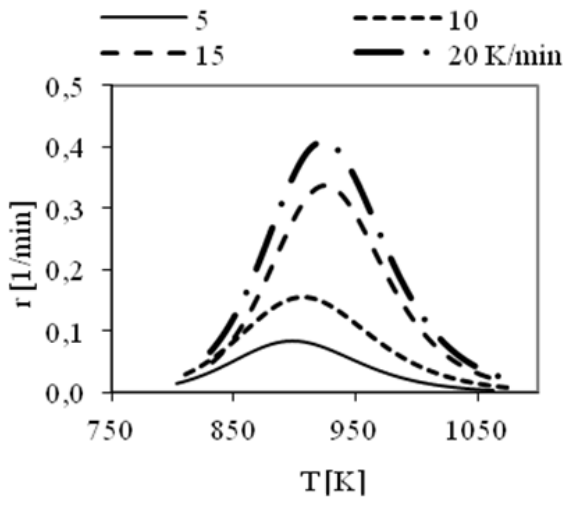

Figure 27. Plots of $r(\alpha, T)$. Oxidation in air of nc-TiC reduced with hydrogen; a) oxidation of $\left.n c-T_{i C}, b\right)$ burning out of elemental carbon formed during the oxidation of nc-TiCx

In this case, full consistency with the theory was obtained. The plots in Figure 27a show that nc-TiCx after reduction with hydrogen was uniform, the process rate increased along with the increase in sample heating rate, and the maximum was shifted into the higher temperature range. In both cases, the process rate, according to the theory, increases from zero for $\alpha(\mathrm{T})=0$, reaches its maximum at the temperature $\mathrm{T}_{\mathrm{m}}$, and then decreases to zero at $\alpha(\mathrm{T}) \rightarrow 0$. The temperature ranges determined for the stages runs in measurement series on the basis of calculations are consistent with the ones determined experimentally.

The obtained results show that the proposed description method of the kinetics of two reactions proceeding simultaneously in a certain range of temperature, allows obtaining a satisfactory accuracy. This method was developed for the needs of processes of oxidation in air of nanocrystalline $\mathrm{TiC}$ and nanocomposites of $\mathrm{TiC} / \mathrm{C}$ with varying carbon content in the matrix, for evaluating the protective qualities of carbon matrix, and also to evaluate and compare the resistance to oxidation of carbide ceramics [17]. In Figure 28 the use of the kinetics knowledge for comparative evaluation of the rate of $\mathrm{TiC} / \mathrm{C}$ nanocomposite oxidation, depending on the carbon content in the matrix is shown as an example. 


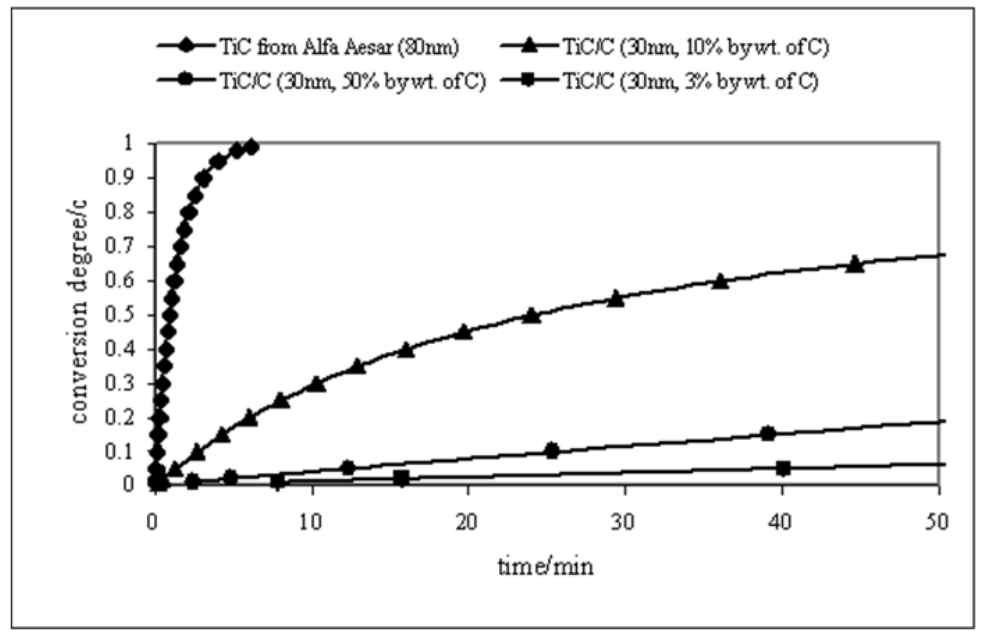

Figure 28. Dependence of conversion degree on time - $\alpha(t) . T=823 \mathrm{~K}$. Oxidation of TiC commercial and TiC/C nano-composites $(30 \mathrm{~nm}$ ) in air. 50, 10, 3 \% by wt. of the carbon contents in composites respectively [17].

\section{Conclusions}

The results of thermal decomposition of $\mathrm{NH}_{4} \mathrm{VO}_{3}$ in dry air have been presented. The measurements were carried out by TG - DSC method. The gaseous products were determined by MS method. Solid products were identified by XRD method. On the basis of measurement results the division of the process into stages has been made and the temperature ranges for stage courses and changes of sample masses in stages were determined. There was demonstrated that decomposition of $\mathrm{NH}_{4} \mathrm{VO}_{3}$ proceeds according to the following equation

$$
6 \mathrm{NH}_{4} \mathrm{VO}_{3} \rightarrow\left(\mathrm{NH}_{4}\right)_{3} \mathrm{~V}_{6} \mathrm{O}_{16} \rightarrow\left(\mathrm{NH}_{4}\right)_{2} \mathrm{~V}_{6} \mathrm{O}_{16} \rightarrow 3 \mathrm{~V}_{2} \mathrm{O}_{5}
$$

In all the stages at different sample heating rates $\mathrm{NH}_{3}, \mathrm{H}_{2} \mathrm{O}, \mathrm{NO}$ and $\mathrm{N}_{2} \mathrm{O}$ were evolved, which were formed as a result of $\mathrm{NH}_{3}$ oxidation. $\mathrm{NO}_{2}$ did not occur among the evolved gases. There should be added that $\mathrm{N}_{2} \mathrm{O}$ was formed mainly during the stage II and III.

While performing the measurements the emphasis was placed on the possibility of obtaining experimental data for description of kinetics of investigated process, in accordance with ICTAC Kinetics Committee recommendations.

In the case of the investigated process, the necessary results for isothermal conditions were not obtained because the measurements for the stage could be performed only in a few temperatures, while at higher temperatures the results were obtained at high conversion degrees.

For non-isothermal conditions the needed data have been obtained. Kinetic calculations were performed using Kissinger's method, isoconversional method and Coats-Redfern method. Applying Kissinger's method the activation energies were determined and the 
kinetic models were assigned for the stages. The stages I and III are well-described by model A2, and the stage II by model A4. It has been also shown that the influence of heating rate of the sample on the course of the process can be compensated, at constant activation energy, by temperature range $\mathrm{T}_{\alpha=0} \div \mathrm{T}_{\alpha=1}$, which is the value determined experimentally. The temperature ranges were given for the stages.

In case of the investigated process applying the isoconversional method the following results were obtained. The E values for the stages I and III (assimetric plots of DTG and HF) changed constantly along with the change of conversion degree. However, in the case of stage II (symmetric plots of DTG and HF), E was practically constant. It seems probable that the isoconversional method compensates the influence of $\beta_{i}$ on the course of the process by changing the activation energy. Theoretically much more interesting is the possibility to compensate the $\beta_{\mathrm{i}}$, at constant activation energy, with temperature range $T_{\alpha=0} \div T_{\alpha=1}$.

While carrying out the calculations using the Coats-Redfern method the activation energies determined by Kissinger's method were used as the base values. Almost constant values of the $\mathrm{A}$ and $\mathrm{E}$ parameters were obtained for the stages for different heating rate of the samples. The verifying calculations were performed. The $\alpha(T)$ and $r(\alpha, T)$ dependencies were determined. The good consistency with experimental data was obtained. The obtained results show that the Coats-Redfern equation is of great importance for the studies of the kinetics of heterogeneous non-catalytic processes

Describing kinetics of the $\mathrm{TiC}_{\mathrm{x}}$ carbonisation and their oxidation, Coats-Redfern's equation was applied kinetic models of stages were identified based on statistical evaluation and compliance to a large extent, of degrees of transformation for stages calculated and determined from measurements. Building the kinetic models of processes, the results of measurements were treated as statistic values. A system of a complex analysis of measurements results was developed with the use of artificial neurone networks. Based on the TG curves four stages have been distinguished. The first, endothermic stage proceeding with mass loss, corresponded to desorption of volatile products, D3 model. The second, exothermic stage proceeding with mass growth, was assigned to oxidation of uncarbonized $\mathrm{nc}-\mathrm{TiC} / \mathrm{C}$ by the oxygen present in argon at trace level, $\mathrm{F} 2$ model. The third endothermic stage, proceeding with mass loss, referred to carbonization of $\mathrm{nc}^{-} \mathrm{TiC} / \mathrm{C}$ and pyrolysis of organic compounds, contained in the raw samples. The pyrolysis of admixtures and carbonization of $\mathrm{nc}-\mathrm{TiC} / \mathrm{C}$ proceeded simultaneously. After completing the carbonization process at the temperature above $1573 \mathrm{~K}$, oxidation of carbonized $\mathrm{TiC}_{\mathrm{x}} / \mathrm{y}$ by oxygen present in argon at trace level was observed, $\mathrm{R} 2$ model.

The third, basic stage preceded in non-isothermal and isothermal conditions; at lower conversion degrees F1 model (first-order reaction) and at the higher conversion degrees (above 0.98) D3 model (three-dimensional diffusion, spherical symmetry, Jander equation) was applied.

Adapting to the description of the processes which took place with the participation of nc$\mathrm{TiC}_{\mathrm{x}} / \mathrm{C}$ the parameters for the process of purification were determined together with the simultaneous carbonization of $\mathrm{nc}^{-\mathrm{TiC}} \mathrm{x}$ in argon, in conditions which make impossible their 
coalescence and growth to micron sizes. Kinetics and by the same, the mechanism of the processes of oxidation of nanocrystalline $\mathrm{TiC}_{\mathrm{x}}$ in form of powder were tested, and they were subjected to evaluation based on the comparison of the rate of oxidation.

\section{Nomenclature}

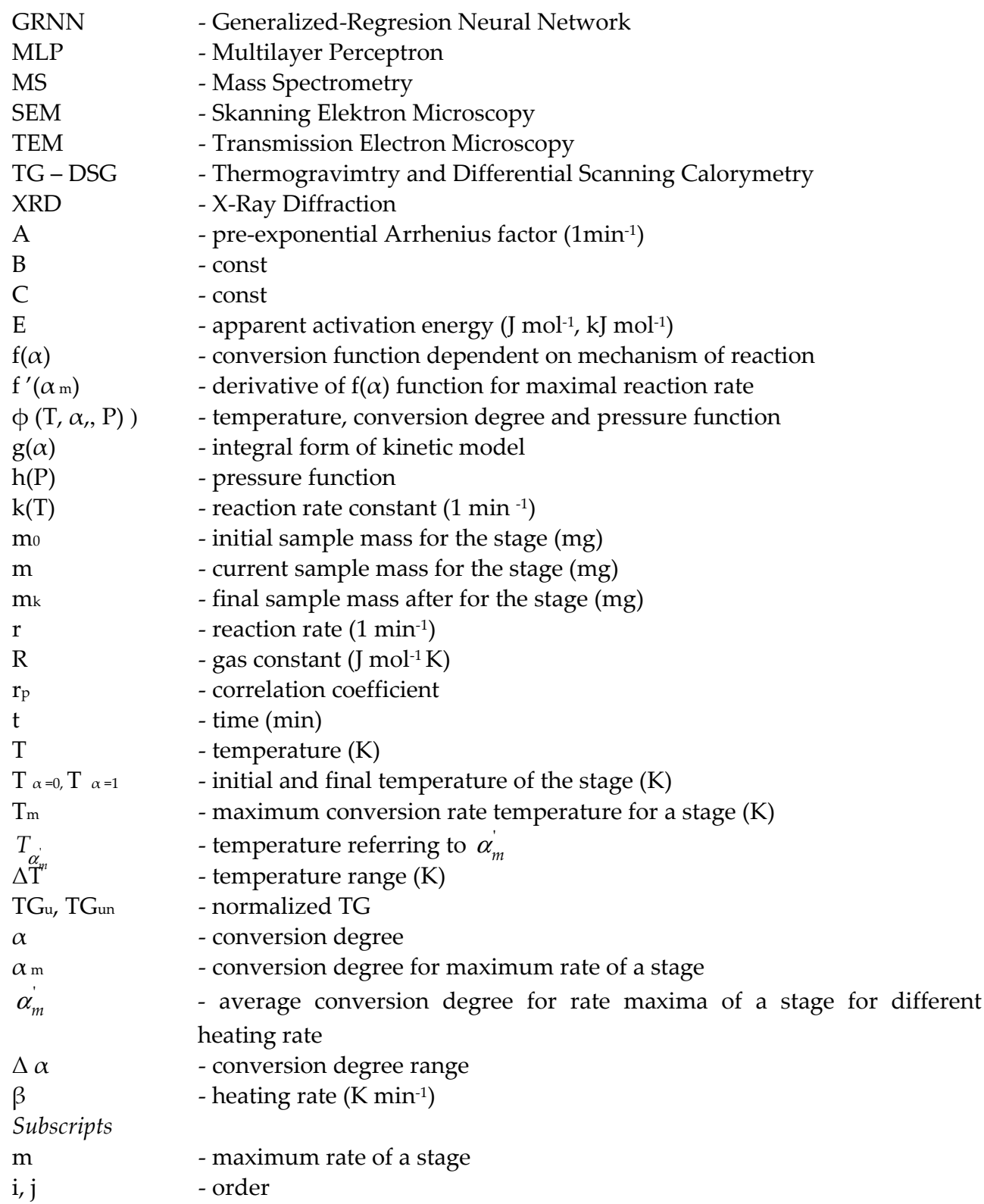




\section{Author details}

Anna Biedunkiewicz

Institute of Materials Science and Engineering West Pomeranian University of Technology, Szczecin, Poland

\section{Acknowledgements}

This work it concerns were partially generated in the context of the MULTIPROTECT project, funded by the European Community as contract No. NMP3-CT-2005-011783 under the 6th Framework Programme for Research and Technological Development. Financial support of part of the work by the Ministry of Science and Higher Education within the Projects No N N507 444334, 2008-2011 and No NR15-0067-10/2010-2013, is gratefully acknowledged.

The scientific support of my teacher professor Jerzy Straszko throughout this work is gratefully acknowledged.

\section{References}

[1] Vyazovkin S, Burnham AK, Criado JM, Perez-Maqueda LA, Popescu C, Sbirrazzuoli N (2011) ICTAC Kinetics Committee Recommendation for Performing Kinetic Computations on Thermal Analysis Data. Thermochimica acta, 520: 1-19

[2] Weimer AW, Nilsen KJ, Cochran GA, Roach RP (1993) Kinetics of carbothermal reduction synthesis beta silicon carbide. AIChE j. 39:493-503

[3] Chaudhurry S, Mukerjee SK, Vadya NV, Venugopal (1997) Kinetics and Mechanism of Carbothermal Reduction of $\mathrm{MoO}_{3}$ to $\mathrm{Mo}_{2} \mathrm{C}$, J alloy comp. 261(1-2): 105-113

[4] Patel M, Subrahmanyam J (2008) Synthesis of Nanocrystalline Molybdenum Carbide $(\mathrm{Mo} 2 \mathrm{C})$ by Solution Route. Mater research bulletin. 43: 2036-2041

[5] Wanjun T, Yuwen L, Xi Y, Cunxin W (2004) Kinetic Studies of the Calcination of Ammonium Metavanadate by Thermal Methods. Ing eng chem res. 43 (9): 2054-2059

[6] Biedunkiewicz A (2009) Aspects of Manufacturing of Ceramic Nanomaterials of TiC/C, TiC, TiC-SiC-C and Ti(C,N)-Si(C,N)-Si3 $\mathrm{N}_{4}$ Type by Sol-Gel Method; Szczecin: West Pomeranian University of Technology, 177p.

[7] Liu CH, Li WZ, Li HD (1996) TiC/Metal Nacreous Structures and Their Fracture Toughness Increase, J. mater res. 11(9): 2231-2235

[8] Thorne K, Ting S, Chi CJ (1992) Reduction of Titanium Dioxide to Form Titanium Carbide. J. mater sci. 27: 4406-4414

[9] Koc R, Folmer JS (1997) Carbothermal Synthesis of Titanium Carbide Using Ultrafine Titania Powders. J. mater sci. 32(12): 3101-3111

[10] Lu Q, Hu J, Tang K, Deng B, Qian Y, Zhou G, Liu X (1999) The co-Reduction Route to TiC Nanocrystallites at Low Temperatures. Chem phys lett. 314(1-2): 37-39

[11] Burakowski T, Wierzchoń T (1999) Surface Engineering of Metals: Principles, Equipment, Technologies, New York: CRC Press, 592p.

[12] Ohring M (1992) The Materials Science of Thin Films, New York: Academic Press, Inc. Harcourt Brace Jovanovich Publishers, 704p. 
[13] Voitovich VB, Laverenko VA (1991) Oxidation of Titanium Carbide of Differency Purity, Soviet metallurgy met ceram. 30 (11): 927-932

[14] Jin Y, Liu Y, Wang Y, Ye J (2010) Synthesis of (Ti, W, Mo, V)(C, N) Nonocomposite Powder From Novel Precursors. Int refract $j$ hard mater. 28: 541-543

[15] Yeh CL, Wang HJ (2011) Combustion Synthesis of Vanadium Borides. J Alloys Compounds, 509: 3257-3261

[16] Mutin PH, Popa AF, Vioux A, Delahay G, Coq B (2006) Nonhydrolytic VanadianTitania Xerogels: Synthesis, Characterization, and Behavior in the Selective Catalytic Reduction of $\mathrm{NO}$ by $\mathrm{NH}_{3}$. Applied catal b: environ; 69 (1-2): 49-57

[17] Biedunkiewicz A, Gordon N, Straszko J, Tamir S (2007) Kinetics of Thermal Oxidation of Titanium Carbide and Its Carbon Nano-composites in Dry Air Atmosphere. J therm anal cal. 88 (3): 717-722

[18] Burnham AK, Weese RK, Wernhoff AP, Maienschein JL (2007) A Historical and Current Perspective on Predicting Thermal Cookoff behavior. J therm anal calorim. 89: 407-415

[19] Biedunkiewicz A, Gabriel U, Figiel P, Sabara M (2012) Investigations on $\mathrm{NH}_{4} \mathrm{VO}_{3}$ Thermal J therm anal cal., 108:965-970

[20] Coats AW, Redfern JP (1964) Kinetic Parameters From Thermogravimetric Data. Nature, 201: 68-69

[21] Vyazovkin S, Wight CA (1999) Model-Free and Model-Fitting Approaches to Kinetic Analysis of Isothermal and Nonisothermal Data. Thermochim acta, 340-341: 53-68

[22] Biedunkiewicz A, Strzelczak A, Chrościechowska J (2005) Non-isothermal Oxidation of TiCx Powder in Dry Air. Pol j chem technol; 7 (4): 1-10

[23] Biedunkiewicz A, Strzelczak A, Możdżeń G, Lelątko J (2008) Non-isothermal Oxidation of Ceramic Nanocomposites Using the Example of Ti-Si-C-N Powder: Kinetic Analysis Method, Acta mater. 56: 3132-3145

[24] Straszko J., Biedunkiewicz A, Strzelczak A (2008) Application of Artificial Neural Networks in Oxidation Kinetic Analysis of Nanocomposites, Pol j chem technol, 10(3):21-27

[25] Galway AK (2003) What is Mean by the Term "Variable Activation Energy" when Applied in the Kinetic Analyses of Solid State Decompositions (Cryptolysis Reaction)? Thermochim acta, 397:249-268

[26] Shimada S, Kozeki M (1992) Oxidation of TiC at Low Temperatures, J mater sci. 27: 1869-1875

[27] Shimada S (2002) A Thermoanalytical Study on the Oxidation of ZrC and HfC Powders with Formation of Carbon. Solid state ionics, 149 (3-4) : 319-326

[28] Shimada S (1996) A Thermoanalytical Study on Oxidation of TiC by Simultaneous TGDTA-MS Analysis, J meter sci. 30:673-677

[29] Shimada S (2001) Interfacial Reaction on Oxidation of Carbides with Formation of Carbon, Solid state ionics, 99: 141-142

[30] Shimada S (2001) Formation and Mechanism of Carbon-containing Oxide Scales by Oxidation of Carbides ( $\mathrm{ZrC}, \mathrm{HfC}, \mathrm{TiC})$, Mat sci forum 369-372: 377-384

[31] Gozzi D, Montozzi M, Cignini PL (1999) Apparent Oxygen Solubility in Refractory Carbides, Solid state ionics 123: 1-10.

[32] Biedunkiewicz A (2011) Manufacturing of Ceramic Nanomaterials in Ti-Si-C-N System by Sol-Gel Method, J sol-gel sci technol. 59: 448-455 